University of Nebraska - Lincoln

DigitalCommons@University of Nebraska - Lincoln

\title{
Physiological Aeroecology: Anatomical and Physiological Adaptations for Flight
}

Susanne Jenni-Eiermann

Robert B. Srygley

Follow this and additional works at: https://digitalcommons.unl.edu/usdaarsfacpub

This Article is brought to you for free and open access by the U.S. Department of Agriculture: Agricultural Research Service, Lincoln, Nebraska at DigitalCommons@University of Nebraska - Lincoln. It has been accepted for inclusion in Publications from USDA-ARS / UNL Faculty by an authorized administrator of DigitalCommons@University of Nebraska - Lincoln. 


\title{
Physiological Aeroecology: Anatomical and Physiological Adaptations for Flight
}

\author{
Susanne Jenni-Eiermann and Robert B. Srygley
}

\begin{abstract}
Flight has evolved independently in birds, bats, and insects and was present in the Mesozoic pterosaurians that have disappeared. Of the roughly one million living animal species, more than three-quarters are flying insects. Flying is an extremely successful way of locomotion. At first glance, this seems surprising because leaving the ground and moving in the air is energetically expensive. We will therefore start with the question: why do some animals spend a substantial proportion of their life in the air? To generate lift, a few key features are required, and yet, animals show incredible diversity in their flight mechanics. We will review constraints imposed by body size including anatomical adaptations of the skeleton, muscles, and organs necessary to stay airborne with a special focus on the wings. Ecology of the aerial organism, such as diet or migration, has diversified flight styles and the physiological adaptations required to optimize performance. For example, animals are exposed to low temperatures and low oxygen pressure at high altitude, whereas overheating can pose a problem at low altitudes. Moreover, aerial prey can be particularly apparent to aerial predators resulting in selection on flight speed and maneuverability of predators and prey. Flight is energetically costly, much more costly than walking, with the majority of the cost dictated by body mass. Hence, adding weight load to fuel flight also adds to the cost of flight. We review energy supply
\end{abstract}

S. Jenni-Eiermann $(\bowtie)$

Schweizerische Vogelwarte, Seerose 1, 6204 Sempach, Switzerland

e-mail: Susi.jenni@vogelwarte.ch

R.B. Srygley

U.S. Department of Agriculture, Northern Plains Research Lab, Agricultural Research Service, Sidney, MT, USA

Smithsonian Tropical Research Institute, Balboa, Republic of Panama

(C) Springer International Publishing AG, part of Springer Nature 2017 
for flight, and special adaptations for long-term flights. Aeroecology has resulted in extraordinary visual and aural sensory systems of predators, which in coordination with the locomotor system are under strong selection to detect and intercept prey in flight.

\section{Box with Definitions}

Aspect ratio of a wing is the ratio of its length to its breadth. A high aspect ratio indicates long, narrow wings (swift, albatross), whereas a low aspect ratio indicates short, stubby wings.

Drag is a slowing force caused by viscosity.

Gliding is powered by gravity. Gliding occurs with no active thrust; a glider must always descend relative to the air it moves through.

Gravity of Earth The relationship between gravitational acceleration and the downward weight force experienced by objects on earth is given by the equation force $=$ mass $\times$ acceleration. Hence the more a body weighs, the more is the gravity.

Maneuverability is the ability to turn in a small radius.

Reynolds Number gives the ratio of pressure (inertial) and viscous contributions to drag, formally defined as (density* speed * characteristic length)/dynamic viscosity. The Reynolds number is important aerodynamically, because at low Reynolds number (small size and/or low speeds), wings tend to have lower lift-to-drag ratios.

Thrust is the forward force produced by the wings. During flight at uniform speed, air meets the bird at the flying speed. To keep flying at the same speed, the bird must generate an amount of thrust equal to the total drag on body and wing in horizontal direction. Therefore, the wings accelerate the air under their control backward to give it a higher speed behind the bird.

Vertical Lift is the upward force produced by wings that counteracts gravity. Because flapping is mostly not horizontal, the upward force is only a fraction of the lift produced by flapping wings.

Wing load is body weight divided by wing area.

This chapter provides a very basic overview of anatomical and physiological adaptions to a life in the air. It is not within the scope of this chapter (and book) to deal with these subjects in depth. For further studies, the reader is referred to the textbooks of aerodynamics of flight and morphology (e.g., Dudley 2000; Alexander 2002; Videler 2005; Pennycuick 2008). There are representatives in nearly all vertebrate classes, such as squirrels, marsupials, lizards, snakes, big-footed frog, and flying fish, which have developed membranes enabling them to glide or to do 
controlled descents. In addition, several invertebrates, such as flying squid, canopy ants (Yanoviak et al. 2005), and bristletails (Yanoviak et al. 2009), are capable of controlled descents, whereas some caterpillars and spiders disperse long distances by ballooning (Taylor and Reling 1986). However, in this chapter, we will treat only animals able to use powered flight and spending a substantial proportion of their life cycle airborne.

\subsection{Why Are Animals in the Air?}

Why do so many animals move into the air? Judging by numbers, flying is extremely successful. Of the roughly one million living animal species, more than three-quarters are flying insects (Schmidt-Nielsen 1997). To leave the ground which supports their weight, they need force to move in the air and to overcome gravity. The advantages of being in the aerosphere are the wide space, whichoutside forests - contains fewer barriers than the ground. Therefore, fast locomotion without a need to maneuver around obstacles is possible. This is of importance when escaping from predators, especially from predators unable to fly. It also allows the rapid location of potential mates, such as the male moth seeking the pheromone-emitting female or the male firefly seeking the luminescent female. However, animals in the air or on the ground are often easier to detect by airborne predators in hunting flights. Signals sent in the open space of the aerosphere, such as the aerial displays of the winnowing snipe or the color pattern on a butterfly's wings, transmit long distances to both conspecifics and potential predators.

The aerosphere is not only used for short flights; many species spend days or even months exclusively airborne. They take advantage of thermic conditions and forage while riding on the wind, such as the petrels. Others migrate each year to their wintering grounds and back, thereby covering thousands of kilometers over partially inhospitable grounds, such as oceans or deserts. Covering such distances within a relatively short time would not be possible on the ground. Flying animals typically move 10-20 times faster than a similar sized animal moves on the ground (Alexander 2002). Also crossings of oceans would be impossible for terrestrial animals.

Finally, some species rely on flight for most of their life. Alpine swifts for instance use the air as their main habitat and spend 200 days continuously in the air (Liechti et al. 2013). They are able to hunt, sleep, and copulate in flight and return to the ground just for breeding. Apparently they do not experience fatigue, sleep deprivation (see Schwilch et al. 2002), muscle damage (only little; Guglielmo et al. 2001), suppression of immunity (none found; Hasselquist et al. 2007), excessive stress hormone levels (none found in healthy birds; Falsone et al. 2009; Jenni-Eiermann et al. 2009), or elevated oxidative stress (Costantini et al. 2007; Jenni-Eiermann et al. 2014). 


\section{$2 \quad$ Anatomical Adaptations: What Is Necessary to Fly?}

The ability to fly requires some general adaptations of the skeleton, since flight is dominated by severe aerodynamic and physiological constraints common to all flyers. For a better understanding of the functional morphology, knowledge of aerodynamics is required. Here, only some very basic rules of aerodynamics will be provided. A flying animal has to generate lift, a force in the upward direction, to offset gravity, a force in downward direction (Fig. 5.1). To move forward through the air, the flyer has to produce a horizontal force, the thrust, thereby overcoming a slowing force, called drag. The direction of the lift is perpendicular to the movement of air over the wing. Newton's laws predict that on average over time the total vertical component of force must equal weight and the sum of the drag forces must be balanced by the generated thrust (Norberg 1990; Videler 2005). Hence, in order to fly, it is crucial that the vertical forces weight and lift and the horizontal forces drag and thrust are balanced.

The following paragraphs will show various morphological adaptations of the skeleton, the forelimbs, and the body shape which different vertebrate classes and families have evolved.

\subsection{Body Shape}

As described above, an efficient flyer should produce as little drag as possible to keep the costs for thrust low. The more streamlined a body is the lower is the drag. And indeed, birds and bats have-in spite of a large number of speciesmaintained to a great deal structural similarity. Birds have streamlined bodies, their forelimbs evolved to wings, and only their hindlimbs are used for walking or perching. The more time a species spends in the air, the more streamlined is its body shape. Bats are not as aerodynamically shaped as birds, but they all have wings and flight muscles (Alexander 2002).

Fig. 5.1 For an animal, such as this pigeon, flying forward at a steady speed without changes in altitude, vertical lift, and thrust counter the pigeon's weight and drag on the body and wings

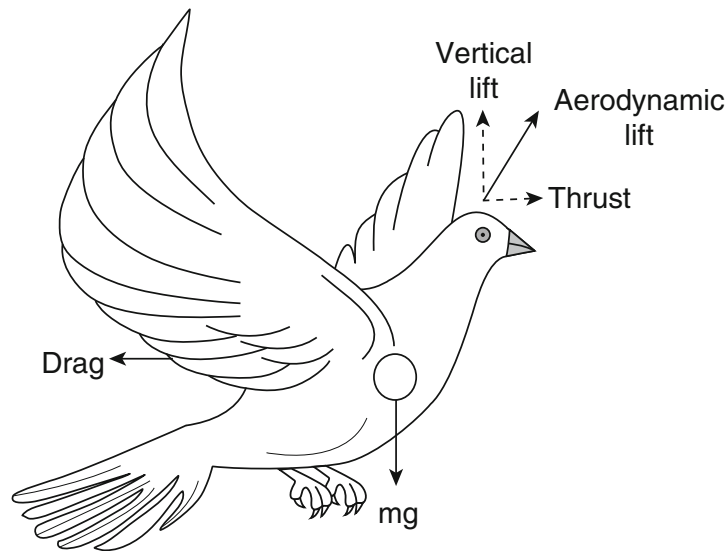


As with birds and bats, insect wings attach to the thorax and the thoracic musculature powers the flapping wings. However, insects evolved their wings independently of their legs, and this may have allowed greater variation of body and wing forms than is observed in bats and birds. The bodies of some insects are fusiform, in part to minimize drag but also to maximize load carried near to the wings. For example, hawkmoths are streamlined to such an extent that they appear like hummingbirds when hovering at flowers. By positioning more mass near to the center of gravity, the rotational moment of inertia is decreased allowing the insect to pitch forward more readily to accelerate its speed or yaw more readily in maneuvers. This is evident in the short, squat body shape of butterflies that fly fast and maneuver to escape predators (Chai and Srygley 1990; Srygley and Chai 1990a; Srygley and Dudley 1993; Srygley and Kingsolver 2000; Kingsolver and Srygley 2000). However, most insects are so small that they operate in a Reynolds number where viscosity dominates over inertial contributions to drag and large variation in body form has little aerodynamic effect.

\subsection{Body Mass}

Flight costs strongly depend on body mass, in bats as well as in birds (Speakman and Thomas 2003). In geometrically similar birds (isometric scaling), theory predicts that the power required for flapping flight increases with about the $7 / 6$ power of body mass, while available power increases only with the $5 / 6$ power of body mass, because larger birds beat their wings at a lower frequency than smaller ones (Pennycuick 2008). This would result in a theoretical limit of about $16 \mathrm{~kg}$ body mass for a flapping flying bird. Indeed, body mass of the heaviest birds known for prolonged powered flight is up to $16 \mathrm{~kg}$ (great bustard Otis tarda), $20 \mathrm{~kg}$ (kori bustard Ardeotis kori), and $22.4 \mathrm{~kg}$ (mute swan Cygnus olor), but this does not mean that heavier birds (and pterosaurs) cannot fly. They might reduce the power needed for flight by soaring in upwinds (in thermals or behind waves). However, it seems that large flapping flyers are not geometrically similar to small flapping flyers and the power for flapping flight actually scales to the power of 0.67 with body mass (Videler 2005).

Therefore, reduction of body mass by developing pneumatic bones is an efficient anatomical adaptation to save flight costs, a strategy found in birds only. Pneumatic bones are filled with air spaces instead of bone and marrow and therefore lighter in weight than similar sized bones of other vertebrates. In skull bones, air spaces arise from nasal passageways, whereas those in the vertebrae, sternum, ribs, pelvis, humerus, and femur are connected to either lung sacs or the lungs directly.

Adding weight load to fuel flight also adds to the cost of flight. When flight fuel is at a premium, as often occurs in long-distance migrants, then natural selection operates to conserve energy (Alerstam et al. 2003). Power saved by minimizing weight (low wing loadings) is compromised by the needs to have mass allocated to flight muscles and fuel to power the long-distance flights. In the bar-tailed godwit Limosa lapponica and the red knot Calidris canutus islandica, birds with 
exceptionally long, nonstop flights, another adaptation to reduce body mass was found. The gut is reduced shortly before departure, apparently to reduce the mass that is not required to sustain flight (Piersma and Gill 1998; Piersma et al. 1999; Landys-Ciannelli et al. 2003). For insects, the oogenesis flight syndrome (Johnson 1969) characterizes many migrants that first migrate and then reproduce. By delaying reproduction, mass that is not allocated to muscle or fuel to power flight is minimized.

Limitations on load might also constrain the diets of flying birds and bats. For example, power required for flight might constrain the evolution of folivory in birds and bats not only because of the added weight of a bolus of leaves but also because leaf digestion typically requires an evolutionary extension of the gut which adds bulk (Dudley and Vermeij 1992). Only a few birds, such as the hoatzin, specialize on leaves and these only fly short distances if at all. However, bats from at least 16 species extract and swallow the juices from leaves and then expel the residual fibers to reduce weight (Kunz and Ingalls 1994).

\section{$2.3 \quad$ Wings}

\subsubsection{Properties of Wings}

All animals that fly under power do so by flapping. The key innovations required for powered flight in animals are therefore adaptations that permit and improve the flapping movements. The wings generate lift by the Bernoulli principle: typically air passes over the dorsal surface faster than it moves under the wing, which generates a low pressure above the wing to offset gravity and generate thrust. This mechanism is known as the bound vortex because the vortex encircles the wing's upper and lower surfaces (Fig. 5.2). Although airplanes also utilize a bound vortex to generate lift, flapping wings are different in that they must generate a new vortex with each downstroke and sometimes also again during the upstroke of the wing (compare Fig. 5.3a, b). Hence, the constraint of stopping and starting the wing

Fig. 5.2 (a) More rapid flow over the wing than under the wing generates lift; the resultant of this differential flow is a bound vortex that encircles the wing. (b) Due to the conservation of momentum, a starting vortex equal and opposite to the bound vortex also develops

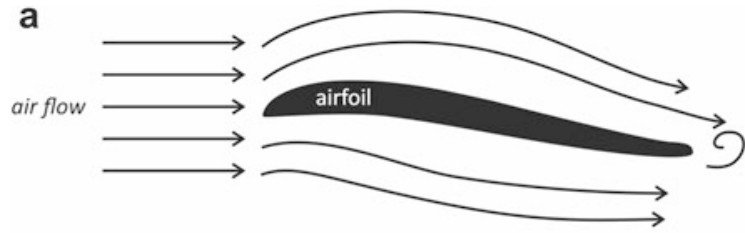

b

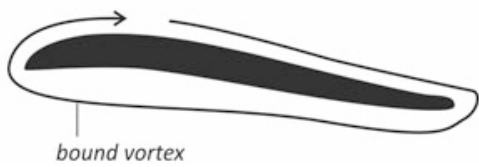


a
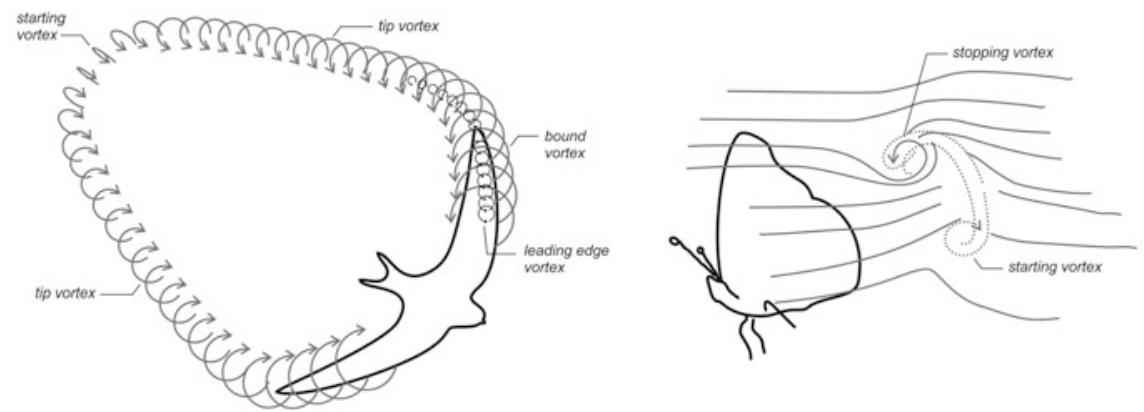

b

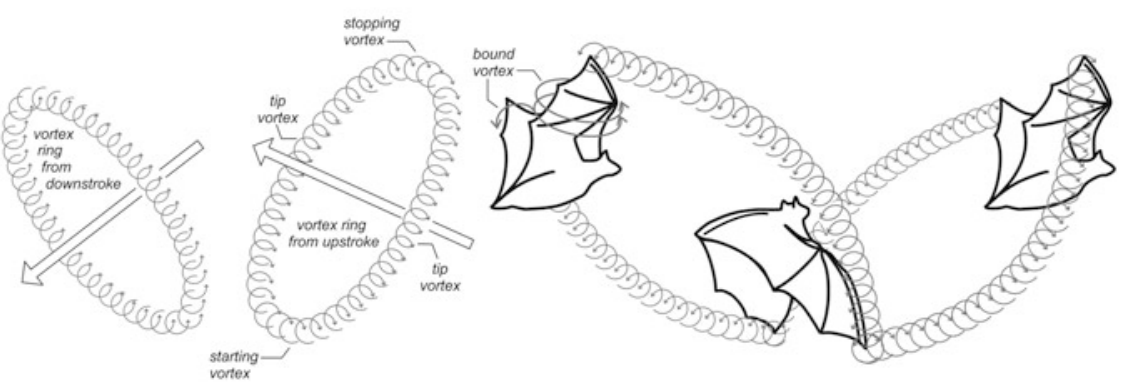

Fig. 5.3 (a) In gliding flight, a swift has a bound vortex encircling the wing along its chord, tip vortices formed from leakage over the wing tips, and a starting vortex left far behind from where the glide first began. Together these make an elongated vortex ring just like a fixed wing aircraft. The swift also has a leading edge vortex (on the upper surface of each wing but shown on only one) that generates additional lift. The swept back wings of the swallow are believed to stabilize the leading-edge vortex at even low angles of attack, as also seen in delta winged aircraft. (b) In flapping flight, sequential views of a bat are drawn with the first at the beginning of the downstroke, the second after it has completed the downstroke and is beginning the upstroke, and the third near the top of the upstroke. Unlike a gliding animal, the starting vortex, tip vortices, and bound vortex are generated with each downstroke of the wing and often during the upstroke as well, as shown here. From the beginning to the end of the downstroke and from the beginning to near the top of the upstroke, the bat is shown generating tip vortices that stretch between the sequential positions of the wing tips. The starting vortex and the bound vortex complete the donutlike ring through which most of the force generated by the circulating air is thrust. At the end of each half stroke, the bat sloughs off the bound vortex as the stopping vortex, one of which is to its left forming a part of the vortex ring generated from the sweep of the wings during the upstroke. Complete rings from the previous downstroke and upstroke form the vortex wake to the left of the bat. The arrow drawn through the vortex ring is a rough estimate of the direction of the force generated by the halfstroke. The downstroke generates most of the vertical lift and some of the thrust. (c) When wings of many butterflies and some other insects clap together at the top of the upstroke, they force a pocket of air out from between them and generate a vortex ring that rotates inward and backward, mainly generating thrust. These tracings of smoke trails from Srygley and Thomas (2002) show a cross section through the ring that is on a plane parallel to the page 
stroke twice in a cycle makes animal flight unsteady and more difficult to model than airplane wings or propellers.

To generate lift, wings have to fulfill some general properties. The wings have to be rigid enough to carry the animal's weight, but they should not be too heavy. They must have the proper shape for producing lift to keep the animal aloft while minimizing drag. The animal must be able to flap the wings with the appropriate motions to produce the thrust that drives it through air. And finally, the shape of a wing should be aerodynamic and be powered with little energy, but also good to control and maneuver and - depending on foraging behavior-allow rapid flights.

Insects typically have membranous wings with fluid-filled veins to keep them rigid while also allowing some insect wings to fold when not in use. Lack of musculature in the wings greatly reduces weight but the wing venation only allows passive conformational changes, rather than the active changes in camber and wing shape employed by birds and bats. Most insects have four flapping wings, but flies only have two. Insect musculature can act directly on the wings for flapping, as in dragonflies and grasshoppers, or indirectly flap the wings by conformational changes in the thorax, as in butterflies, bees, and flies.

Some insects (hawkmoths: Ellington et al. 1996; butterflies: Srygley and Thomas 2002; dragonflies: Thomas et al. 2004; bees: Bomphrey et al. 2009) and some birds (swifts: Videler et al. 2004; hummingbirds: Warrick et al. 2005) and bats (Mujires et al. 2008) are known to generate extra lift with leading-edge vortices that corkscrew from the bases of the wings out to the wing tips (Fig. 5.3a). Generating the leading edge vortex requires a delayed stall that causes additional drag. So the leading edge vortex is utilized mostly during take-offs, slow flights, or maneuvers and less in fast, steady flight when sufficient air is moving across the wing to generate the lift required. However, the swept-back wings of swifts may allow maintenance of the leading-edge vortex at low angles of attack so that it can even be used at fast flight speeds (Fig. 5.3a, Videler et al. 2004).

There are other mechanisms that insects use to generate lift more readily. Some butterflies (Ellington 1984) and flies (Lehmann 2008) clap their wings together at the top of the upstroke (Fig. 5.3c), which causes air to begin to move across each wing pair's dorsal surfaces, and then they fling their wing apart so that a bound vortex equal and opposite to one another in circulation is generated on each of the two wing pairs (the clap and fling, Ellington 1984). Flies (Dickinson et al. 1999; Birch and Dickinson 2003) and butterflies (Srygley and Thomas 2002) are able to capture energy from their wake, which depending on the passing of the wing across the wake can generate lift in nearly any direction and potentially result in rapid maneuvers. The independent movement of the dragonfly's four wings allows control over the fore- and hindwing stroke cycles so that each wing can interact with the wake of its pair (Lehmann 2008). Wakes of insects persist only briefly for a short distance behind the wings. However, large or fast flying birds generate wakes that extend several wing spans and persist for tens of wingbeats (Swartz et al. 2008). These wakes are exploited to enhance lift of neighboring birds in the characteristic V-formation of migrating flocks (e.g., ibises, Portugal et al. 2014) but not in the less structured flocks of pigeons (Usherwood et al. 2011). 


\subsubsection{How Does Ecology Affect Flight Type and Wing Morphology?}

The ecology of the aerial organism, such as foraging or migration, has diversified flight styles and the anatomical and physiological adaptations required to optimize flight performance. A given species might use different flight types under different circumstances. However, one flight type mostly dominates depending on the habitat where the animal lives (Alexander 2002) and its ecology. Aeroecology uniquely provides an environment where strong selective forces on traits that pertain to flight have been identified and the evolution of power and performance in flying organisms can be investigated. This approach proves useful because it provides empirical data to test biomechanical theory. In addition, theory may be used to generate models of optimality and ideally map traits on an adaptive landscape to identify trade-offs and other evolutionary constraints on flight.

As discussed above, flight is energetically costly with the majority of the cost dictated by body mass. Therefore, body mass is a factor affecting flight style. Large birds expend energy at rates close to the limits of their abilities while sustaining flight in still air. It is therefore not surprising that most large flying birds spend more time on low-cost gliding flight than in expensive flapping flight. Smaller birds in comparison have a surplus of power that can be used to improve acceleration, load carrying ability, or maneuverability. Another way to save energy by flight style is the intermittent mode of flight as finches or skylarks use. They alternate between flapping and folding the wings. Whenever the drag due to the air friction on the outstretched wings exceeds the drag due to lift, they can save energy when the wings are folded a part of the time. This can be true only for birds that fly at speeds well in excess of their minimum-drag speed and therefore it can only be true for small birds with plenty of power to spare (Bicudo et al. 2010).

Predator-prey interactions provide a context where maneuverability is under strong selection. Bats are unable to detect echoes from small insects until 1-5 m distance, which makes maneuvering to capture extremely important (Jones and Rydell 2003). Both a small turning radius and the ability to roll into a bank quickly are aspects of maneuverability (Norberg and Rayner 1987). However, in the capture of mobile prey, linear acceleration is another important feature of capture success.

For birds and bats, large, long wings reduce the turning radius in banked turns, whereas rolling into the turn is improved by positioning more wing mass near to the axis of rotation. In swifts and swallows, linear acceleration is favored by high wing loading and low aspect ratio, which puts these features in direct conflict with those that minimize turning radius (Warrick 1998). For bats, maneuvering has probably been a strong selective force to limit body mass (Jones and Rydell 2003). Maneuverability is inversely related to mass and wing span of leaf-nosed bats, whereas it improves in those with wings that permit deeper wing cambering (Stockwell 2001). Maneuverability is also achieved by low wing loading and positioning more wing mass near to the wing base, lowering the rotational moment of inertia and improving acceleration in high speed turns. Bats that fly more slowly may maneuver well at low speeds if wing area is positioned far from the wing base so that strong asymmetrical forces can be generated in turns (Swartz et al. 2003). 
Fast and highly maneuverable flight that characterizes many insect species is one means of escape for those species that are highly sought by predators. Perhaps less well known is the slow, steady flight of many distasteful species, which may be a cue for predators that the insect is not worth pursuing (Chai and Srygley 1990; Srygley and Dudley 1993; Srygley and Kingsolver 1998). Allocation of more mass to the thoracic musculature and less to the abdomen is a common feature of butterflies that are palatable to birds, whereas those that are distasteful have smaller muscles and consequentially are able to allocate more mass to reproduction (Srygley and Chai 1990a; Marden and Chai 1991). Selection by aerial predators also constrains both the palatable species' spatial niches and their thermal physiology so that they operate at higher body temperatures relative to those of distasteful butterflies (Srygley and Chai 1990b). Moths also come in two flavors-palatable and distasteful - with some of the latter possessing visual signals to birds and audible warning signals to bats (Ratcliffe and Nydam 2008). Hence, we would predict that palatable moths that need to take evasive maneuvers and distasteful ones also have distinct flight styles and morphologies related to maneuverability.

\section{Constraints of Altitude}

In a stationary atmosphere from sea level to $11 \mathrm{~km}$, mean air temperature drops monotonically $\left(6.5^{\circ} \mathrm{C}\right.$ per $\mathrm{km}$ above ground level) with altitude at a given time and location, air pressure and the partial pressure of oxygen decline exponentially, and air density also declines (Fig. 5.4). More typically, the aerosphere is not stationary and is dotted with warm air rising in thermals, downdrafts of cooler air, and inversion layers where temperature increases with altitude. Birds and insects use currents generated by spatial differences in air temperature and the occurrence of thermals to reduce costs of flight (Westbrook 2008). However, the lower temperatures and limited $\mathrm{O}_{2}$ aloft might also constrain flight height. For example at $5500 \mathrm{~m}$ above sea level, air pressure and hence $\mathrm{O}_{2}$ partial pressure is only $50 \%$ of that at sea level. Hummingbirds are unable to hover when the oxygen concentration is reduced to $11-14 \%$, corresponding to the $\mathrm{O}_{2}$ partial pressure at approximately $5500 \mathrm{~m}$ (Chai and Dudley 1996; Altshuler and Dudley 2003). Other birds spend long periods at these elevations and hence with about half the $\mathrm{O}_{2}$ partial pressure available to sea level residents. They are highly tolerant to hypoxia to levels that are deleterious to mammals. The reduction of $\mathrm{O}_{2}$ partial pressure is to some extent counteracted by an increase in the gaseous diffusion coefficient which varies in inverse proportion to total pressure. Nevertheless, the question is: how do birds and insects manage to meet high aerobic demands at high altitudes?

How to avoid hypoxia Birds have evolved numerous traits for enhanced $\mathrm{O}_{2}$ uptake and delivery from the pulmonary system to the circulating blood and the muscles fibers. Here we will pick out only some traits. For a review, please see, e.g., Scott et al. (2015). 
a

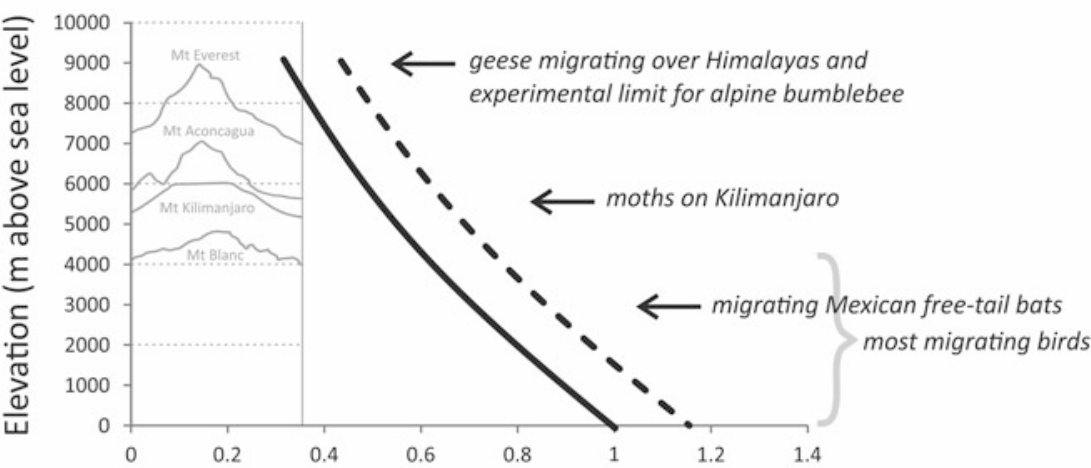

Atmospheric pressure (solid line) and air density (dashes)

b

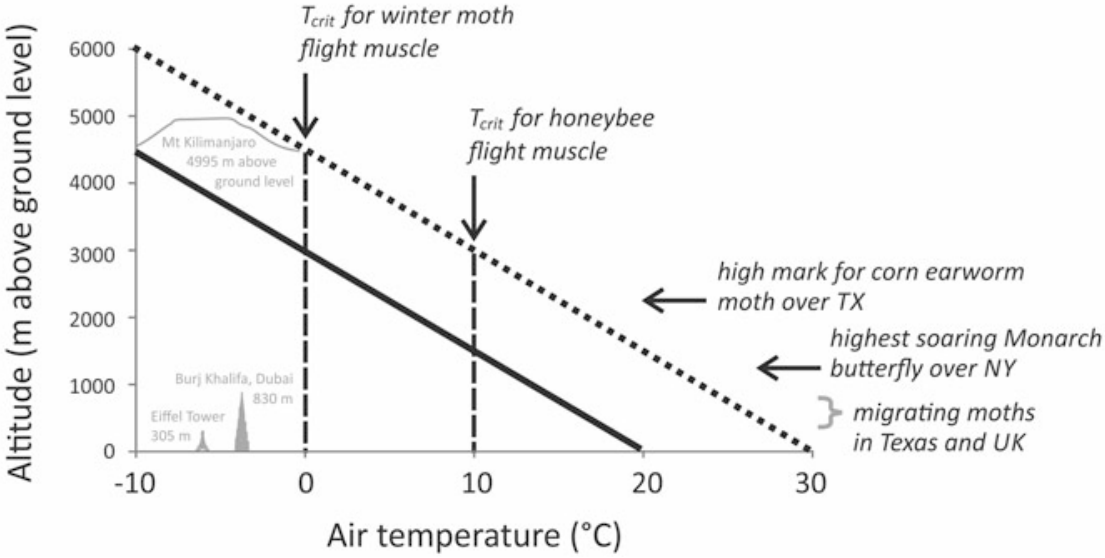

Fig. 5.4 (a) The decline in air pressure (atm) and air density $\left(\mathrm{kg} / \mathrm{m}^{3}\right)$ with elevation. Air density is also a function of temperature and relative humidity, and so to illustrate the change with elevation, we have assumed a temperature of $30{ }^{\circ} \mathrm{C}$ at sea level and $20 \%$ relative humidity. Profiles show elevations of select mountains around the world. Representative elevations for bar-headed geese migrating over the Himalayas and Mexican free-tailed bats migrating in Colorado are indicated with arrows, and the range at which most birds migrate is indicated with brackets. The maximum elevation that moths are active on Mt. Kilimanjaro is indicated with an arrow as is the experimental limit for bumblebee flight. (b) The decline in ambient temperature $\left({ }^{\circ} \mathrm{C}\right)$ with altitude in a stationary atmosphere, assuming a temperature of 30 and $20^{\circ} \mathrm{C}$ at ground level. Representative altitudes for ground-based radar-detected moth migrations are indicated with brackets. The highest records for a Heliothis zea moth (Westbrook 2008) and a Danaus plexippus butterfly (Gibo 1981) are indicated with arrows. Profiles show heights of human-made constructions and also the height of Mt. Kilimanjaro, a free-standing volcano that rises from its base at $900-5895 \mathrm{~m}$. As a rough indication of the maximum altitude at which the winter moth and honeybee can fly above ground, we indicate the lower critical temperature $\left(T_{\text {crit }}\right)$ for flight muscles of winter moths and honeybees to contract (Esch 1988). However, $T_{\text {crit }}$ is based on muscle temperatures and not air temperatures, and so it is possible that these insects could continue to fly at altitudes with air temperatures lower than these lower critical temperatures ( $\left.T_{\text {crit }}\right)$, as long as their muscle temperature remained above $T_{\text {crit }}$ and the muscles were generating sufficient power for flight 
The most important advantage of birds over most other terrestrial vertebrates is the structure and function of their respiratory system. Bird lungs communicate with air sacs that extend throughout the body, thereby increasing the total volume of the respiratory system about three times to that of a mammal of comparable size. Moreover, the parabronchi (finest branches of the bronchial system) permit a continuous, passage of air. The unidirectional flow through the gas-exchange units of avian lungs and the arrangement of airway and vessels create a crosscurrent gas exchanger attaining a superior efficiency for gas exchange (Scheid et al. 1972; Maina 2006). Another advantage of birds - in contrast to mammals - is their high ventilation rates in hypoxia. More rapid breathing lowers blood $\mathrm{CO}_{2}$ partial pressure $\left(\mathrm{PCO}_{2}\right)$, which in turn restrains the hypoxic ventilatory response and can lead to an alkalosis of the blood. However, birds tolerate a greater depletion of blood $\mathrm{CO}_{2}$, either with the capacity to restore blood $\mathrm{pH}$ rapidly and offset changes in blood $\mathrm{PCO}_{2}$ or with a brain vasculature that is insensitive to low carbon dioxide levels in the blood (hypocapnia) (Scott 2011).

These were two examples of physiological traits helping all bird species to overcome low oxygen pressure. There exist also special adaptations in birds flying at extreme altitudes. The best studied species in this respect is the bar-headed goose Anser indicus, which was observed flying in the Himalayas at an altitude of $9000 \mathrm{~m}$. For this or other highland species, additional adaptations were found in all steps of the $\mathrm{O}_{2}$ transport pathway. During flight in hypoxia, the hypoxic ventilatory response is enhanced and the breathing pattern is more effective due to deeper breaths (bar-headed goose; Scott and Milsom 2007). Lungs are larger and the surface area for diffusion is increased (Carey and Morton 1976; Scott et al. 2011). In several high-altitude species, hemoglobin with higher baseline affinity for $\mathrm{O}_{2}$ (McCracken et al. 2009) and an increase of the $\mathrm{O}_{2}$ flux to the mitochondria were found. Finally, in comparisons with lowland birds, aerobic capacity within the flight muscle was higher and mitochondrial ATP production more strongly regulated, such as in the movement of ATP equivalents between sites of ATP supply and demand (reviewed in Scott 2011).

Bats do not have these adaptations; nevertheless, they fly with about the same oxygen consumption as birds (eight- to tenfold increase of resting metabolic rate). However, they do not reach altitudes as some bird species do and there are also no bat species known flying for months without resting.

Insect flight muscle is one of the most active muscle types and has a large density of mitochondria providing this exceptional aerobic capacity (Crabtree and Newsholme 1975). Gas exchange occurs in a branching system of tracheae that originate at the body surface in spiracle openings and interact directly with the mitochondria via the tracheoles. Changes in thoracic volume associated with flapping compress air sacs and trachea to actively ventilate the muscles. In some insects such as bees and wasps, abdominal pumping is used to augment ventilation independent of flight muscle activity (Harrison and Roberts 2000). At rest, American locusts Schistocerca americana double abdominal pumping frequency and increase tidal volume to tolerate $\mathrm{O}_{2}$ partial pressure as low as $1.8 \mathrm{kPa}$ (Greenlee and Harrison 2004). Dragonfly flight was not affected by oxygen levels as low as $10 \%$, but few insects initiated flight in mixtures of $5 \% \mathrm{O}_{2}$ (Harrison and Lighton 1998). 
Adaptations to low air density Flying in less dense air requires expansion of wing area (lower wing loading) or changes in wing kinematics to generate sufficient lift. In air made less dense while $\mathrm{O}_{2}$ partial pressure was held constant (normoxic), hummingbirds increased stroke amplitude but showed only a slight increase in wing beat frequency when hovering (Altshuler and Dudley 2003). Wing beat frequency and airspeed of nocturnal migrating birds increased with altitude (Schmaljohann and Liechti 2009). Honeybees compensated for low-density, normoxic air by increasing stroke amplitude while holding wing beat frequency constant (Altshuler et al. 2005). By increasing stroke amplitude, high-altitude bumblebees were capable of hovering in air with density and $\mathrm{O}_{2}$ partial pressure corresponding to an altitude of $9000 \mathrm{~m}$ (Dillon and Dudley 2014).

Adaptations to extreme temperatures In high altitudes, low oxygen pressures and low temperatures might constrain flight ability. In contrast, at low altitudes high temperatures and low relative humidity might limit endurance flight. Therefore, birds migrating long distances prefer to fly at night. However, temperatures of more than $30{ }^{\circ} \mathrm{C}$ and relative humidities as low as $30 \%$ can also occur at night. For example, these stressful conditions were measured between 0.5 and $1.5 \mathrm{~km}$ above sea level over the Western Sahara during the autumn migration of $64 \%$ of the nocturnal songbirds at that location (Schmaljohann et al. 2009). In wind tunnel experiments, an ambient temperature of $25{ }^{\circ} \mathrm{C}$ already seems to constrain flight. Birds either refuse to fly (e.g., Ward et al. 1999; Engel et al. 2006) or were dehydrated after a $2 \mathrm{~h}$ flight (Biesel and Nachtigall 1987). Migrants crossing deserts or oceans have no possibility to drink and rely on the production of metabolic water. Water gain produced by fat and protein oxidation should compensate for water loss via the lungs (see also Sect. 4). To avoid water loss, birds could choose altitudes with low temperatures. However, this might not always be the better solution. In the Western Sahara, the most favorable winds for autumn migration were found at low altitudes where temperatures were high, while unfavorable winds prevailed at high altitudes. According to Schmaljohann et al. (2009), wind direction was the key factor determining flight altitude. How the migrants managed not to become dehydrated is still under debate. One explanation might be that wind tunnel experiments are more stressful than free flights and overestimate water loss.

The foraging activities of bats are predominantly (but not exclusively) restricted to twilight and night. One hypothesis to explain the nocturnal activity of bats is the "hyperthermia hypothesis" presuming that solar radiation might drive body temperature to critical levels (e.g., Speakman et al. 1994). In contrast to birds, bat wing membranes are not insulated by feathers, have a low degree of reflectance, and indeed absorb up to $90 \%$ of short-wave solar radiation (Thomson and Speakman 1999). The core body temperature actually increases by $2{ }^{\circ} \mathrm{C}$ when flying at daylight (Voigt and Lewanzik 2011). Hence, solar radiation might be one factor driving bats into the nocturnal niche.

Larger insects generate substantial metabolic heat in flight and can maintain body temperatures elevated above ambient temperature, whereas the body temperature of small insects varies with that of the surroundings. Nocturnal insects are 
often layered at altitudes with the warmest airstreams (Reynolds et al. 2005; Westbrook 2008). Aphids fly in warmer updrafts sufficiently to remain neutrally buoyant and free-fall in cooler downdrafts (Reynolds and Reynolds 2009). Even larger insects in updrafts will reach an altitude at which convective cooling is too great to maintain an elevated body temperature, and they will cease flapping and free-fall.

Note that reduced atmospheric pressure and cold temperature may interact to further reduce flight performance. For example, the decline in flight performance of Drosophila melanogaster in atmospheric pressures that were similar to highaltitude conditions was more pronounced at colder temperatures (Dillon and Frazier 2006). Developmental temperature may also broaden the temperatures and hence the altitudes at which insects may be active. For example, tephritid flies that develop at lower temperatures have greater flight performance across a wider range of temperatures than those developing at high temperatures (Esterhuizen et al. 2014).

Effects of winds Wind speeds increase exponentially with height above ground up to several $100 \mathrm{~m}$. Because most insects are small, wind speeds typically exceed maximum flight speed of the majority of insects, which have little chance to move long distances above the vegetation other than with the winds. The selection of favorable winds for take-off indicates that aphids and other small insects are not simply dispersing passively.

In contrast, larger insects, birds, and bats fly faster and can direct their movement independently of winds to a greater height above the ground (i.e., their flight boundary layer is broader; Srygley and Dudley 2008). However, they all require a ground reference to know their wind displacement. Hence, activity during the daytime may be necessary for drift compensation. In addition, an animal's visual system may limit the altitude at which a ground reference may be resolved. For example, the limited ability of the insects' compound eyes to resolve landmarks from a distance limits the height at which they are able to compensate for drift more so than the visual acuity of birds.

As flight height above ground increases, an animal's ability to compensate for wind drift decreases. However, insects, birds, and bats may all fly above their respective flight boundary layer to take advantage of favorable winds. For example, noctuid moths, principally Spodoptera frugiperda and Helicoverpa zea migrating seasonally in Texas, are most abundant at 400-600 m above ground level where their migration is assisted by a low-level wind jet and where they also attract foraging bats (Westbrook 2008; McCracken et al. 2008). Even above their flight boundary layer, large nocturnal moths, such as Autographa gamma, compensate in part for being blown off course by the wind (Chapman et al. 2008). However, they too might use a ground reference in the contemporary English landscape where artificial lights at ground level could serve as beacons for partial course correction. 


\section{$4 \quad$ Energy Requirements of Flight and Flight Physiology}

Flight is a very costly form of locomotion, because it is performed at a very high metabolic rate. In contrast to walking, the relationship between speed and energy expenditure during flapping flight is U-shaped. A walking animal can slow down to reduce energy expenditure. A flying bird, however, cannot escape a certain level of power output, determined by the lowest point of the U-shaped power curve. Even at this minimum, the metabolic rate of flying birds is about twice the maximum rate of exercising small mammals and is among the highest in all vertebrates (Butler et al. 1998). Oxygen consumption rates of flying insects are 3-30 times greater than those of terrestrial ones of the same body mass at the same body temperature (Harrison and Roberts 2000).

\subsection{Powering Flight}

Powering short burst flight The amount of energy and the type of fuel used for flight depend on the flight duration but also on the flight style. For short burst flights, typically hunting or escape flights, birds have to rely on energy that is available instantaneously. An immediate source of energy is adenosine triphosphate (ATP). ATP is the only substance the muscle proteins can use directly. However, only small amounts are present in the muscle (Schmidt-Nielsen 1997). Another source of immediate energy is the organic compound creatine phosphate. It is present in larger amounts than ATP, but it might last only for some seconds of flight (SchmidtNielsen 1997). For short flights, glycogen, stored in skeletal muscles, will be mobilized. It contributes substantially to energy expenditure at the onset of flight before lipids are fully available (Rothe et al. 1987; Schwilch et al. 1996; Gannes et al. 2001; Jenni-Eiermann et al. 2002). However, the amount of glycogen stored is very small (e.g., Marsh 1983) and can quantitatively not serve as a fuel complementing lipids during endurance flight (see below). In the absence of sufficient oxygen, the muscles can depend on anaerobic glycolysis and oxidize glycogen to lactic acid. The quick muscle contractions are made possible by the fast glycolytic fibers. However, anaerobic glycolysis cannot be continued for long because lactic acid accumulates and impedes muscular activity (Schmidt-Nielsen 1997).

Most insects have flight muscle that is directly stimulated to contract by nerve impulse (called non-fibrillar or synchronous). Flies, bees, wasps, and some beetles possess fibrillar (or asynchronous) flight muscle that contracts faster than the nervous stimulation with nerve impulses only required to initiate and maintain muscle contraction. Contraction rates and wing beat frequencies are higher in insects with asynchronous flight muscles, and yet this enhanced performance comes with little cost, because mass-specific metabolic rates are similar to those with synchronous flight muscles (Harrison and Roberts 2000).

Many insects fuel flight with carbohydrates, which are stored as glycogen in the fat body and other tissues and converted to trehalose to pass into the hemolymph. 
Circulating trehalose is then converted to glucose in the muscles. Relative to using lipids, fueling of flight with carbohydrates requires more frequent stops to ingest sugars. Assuring rapid uptake of glucose from the gut, the low concentration of blood glucose is maintained by absorption of glucose into the fat body and conversion to trehalose or glycogen for storage (Steele 1985).

Powering endurance flight Migratory endurance flight of birds is performed at a high metabolic rate and can be maintained for hours and up to days in certain species. Moreover, most bird species (except aerial feeders) do not feed or drink during endurance flight and, thus, have to rely exclusively on body stores of energy and water. The power needed to carry additional weight in flight is much higher than when walking or swimming (Schmidt-Nielsen 1984). Hence, it is of paramount importance that the energy density of stored fuel is high. Lipids are the optimal fuel for flight because the energy density of stored lipids is more than seven times higher than that of glycogen and protein. In terms of high energy phosphate (e.g., ATP), fat from adipose tissue yields eight times more chemical energy than wet protein, and 8.2-10.3 times more than glycogen (Jenni and Jenni-Eiermann 1998). This is chiefly because fat stored in adipose tissue contains only about $5 \%$ water (Piersma and Lindström 1997), compared with $70 \%$ or more for muscle tissue or stored glycogen. Another advantage of adipose tissue is its comparatively low maintenance costs (e.g., Scott and Evans 1992).

However, there are a number of shortcomings of lipids as a fuel during flight. Lipids are not readily available at the onset of flight but need some time to be mobilized from adipose tissue. With their low aqueous solubility, free fatty acids must be transported by soluble protein carriers at every step from adipose tissue to the mitochondria of the flight muscles (Fig. 5.5a). Lipid transport is likely to limit fatty acid oxidation in birds, as it does in mammals (Weber 1992; McWilliams et al. 2004). Finally, fatty acids cannot cover all of the needs (e.g., glucose for the central nervous system) and therefore a minimum amount of requirements needs to be met by glucose (either derived from glycogen stores or via gluconeogenesis from amino acids or glycerol) and protein. Also intermediates of the citric acid cycle, needed to oxidize fatty acids, are constantly drained away and need to be replaced from carbohydrates or certain amino acids (anaplerotic flux; Dohm 1986; Sahlin et al. 1990). Therefore, the energy supplied by lipids needs to be complemented by an inevitable minimum amount of protein or carbohydrates.

For insects, lipids are stored as triglycerides in the fat body. Both lipids and carbohydrates are used to fuel the initial flight of the migratory locust Locusta migratoria. However, during the first $30 \mathrm{~min}$, hemolymph trehalose levels decrease by $50 \%$, while blood lipid titers increase to its highest levels (Steele 1985). Triglycerides are converted to diglycerides for release from the fat body into the hemolymph where adipolipoproteins reversibly attach and transport each diglyceride molecule from fat body to muscle (Fig. 5.5b). After steady-state flight is reached for locusts, trehalose provides $25 \%$ and lipids $75 \%$ of the fuel.

A few insects fuel flight with the amino acid proline. Some beetles, such as Leptinotarsa and Pachnoda, use a combination of carbohydrates and proline for 

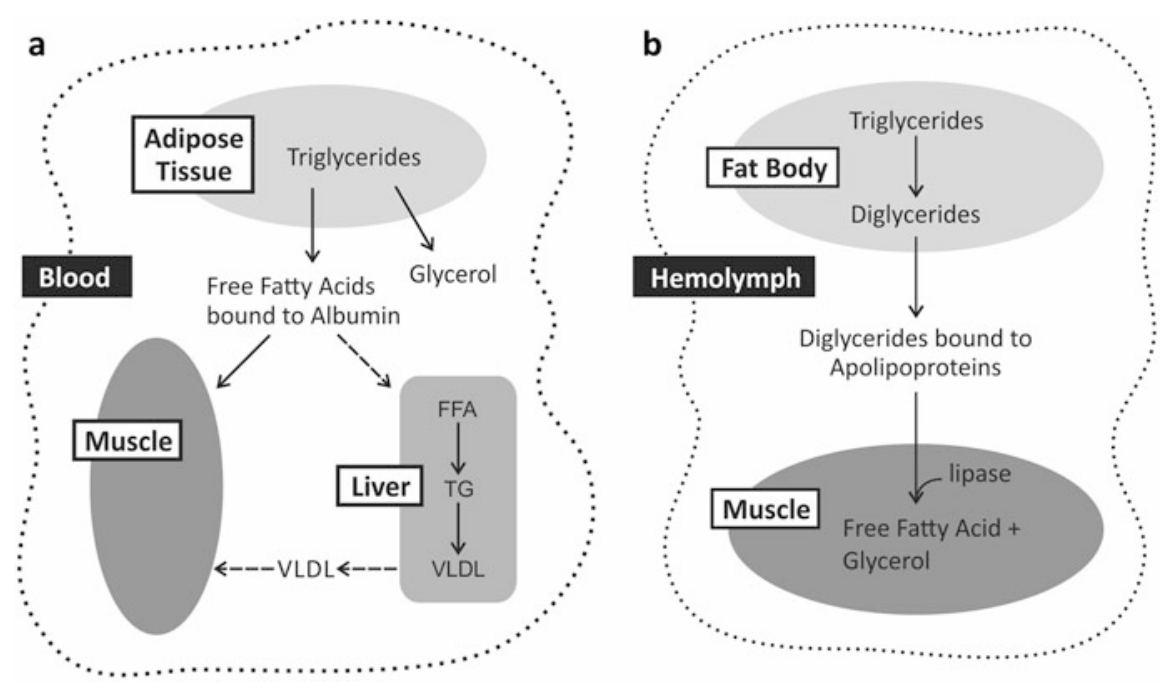

Fig. 5.5 The pathways for conversion of stored lipids (triglycerides, TG) to forms that can be transported to the flight muscles are shown for (a) birds and (b) insects. Due to constraints on the density of free fatty acids (FFA) bound to albumin carried by the blood and the high metabolic demands of migratory flights, very-low-density lipoproteins (VLDL) manufactured in the liver are also used by small passerine birds to transport lipids to the flight muscles

flight, whereas the tsetse fly Glossina oxidizes proline almost exclusively (Goldsworthy and Joyce 2001). Proline oxidation in the flight muscles yields alanine, which circulates to the fat body where stored lipids are utilized to recycle alanine back to proline. Proline is highly soluble in hemolymph allowing it to fuel flight without the transport mechanism required for lipids. Hence, proline can serve to fuel both trivial and prolonged flights. In addition, proline yields about the same energy as lipids and several times more than glucose (Goldsworthy and Joyce 2001).

Proteins have no special storage form. Apart from a small free amino acid pool, all proteins serve specific functions in the body. Therefore, an appreciable amount of protein catabolism inevitably results in functional loss. In birds, it was shown that proteins are catabolized as a complement to lipids for various reasons (Jenni and Jenni-Eiermann 1998): to supplement endogenous protein turnover and repair (there is moderate flight-induced muscle damage; Guglielmo et al. 2001), to provide gluconeogenic precursors, to refill citric acid cycle intermediates (anaplerotic flux) for oxidation of fatty acids, and to provide water (see below). Finally by catabolizing flight muscles during flight, the mass of the flight muscles is constantly adapted to the decreasing body mass and energy needs as fuel stores are depleted (Pennycuick 1998).

The optimal composition of fuel types for migratory endurance flight appears therefore to be a maximum of lipids and a minimum of protein; glycogen does not play a critical role. The question is how well can birds, during their strenuous 
endurance flight, maximize lipid use and minimize protein catabolism. While mammals during strenuous endurance exercise run on carbohydrates and fat as major fuels, with negligible amounts of protein (Roberts et al. 1996), endurance flight of birds is fueled with about $95 \%$ energy derived from lipids and about 5\% derived from protein (Jenni and Jenni-Eiermann 1998). This pattern is particularly interesting since endurance flight is performed at $60-85 \%$ of maximum respiratory rate, and even more when birds are loaded with fuel (Guglielmo et al. 2002). Therefore, endurance flight of birds is fueled very differently from mammalian running.

In birds, it is expected that the optimum ratio of fat to protein stored before, and used during, migratory flight primarily depends on the migration strategy (in particular on the length of nonstop flights) and the risk of dehydration during flight. The higher the need to carry large fuel stores and the lower the risk of dehydration, the better should the organism be tuned for high lipid utilization.

In conclusion, migrating birds are unique in that they fuel endurance flight with the highest possible percentage of energy derived from fat oxidation. As a consequence, their metabolism shows remarkable adaptations to push lipid mobilization, fatty acid transport, and oxidation during flight to a maximum.

\subsection{Adequate Energy Supply During Flight}

During endurance flapping flight, the metabolism is greatly increased to meet the high energetic costs of flight, which are 8-18 times higher than basal metabolic rate for flapping flyers (lower in aerial feeders and seabirds; Videler 2005). On the other hand, a small reduction of flight costs may be obtained by hypothermia (Battley et al. 2001; Butler and Woakes 2001).

In contrast to mammals, which derive most of lipids and glycogen from stores within muscle cells (Weber et al. 1996a, b), birds store negligible amounts of fuel within the working muscles. Therefore, bird flight is fueled via the circulatory system from stores outside the flight muscles. However, at the onset of flight, when extramuscular lipids and protein are not yet available, intramuscular and hepatic carbohydrates are mainly used, while fatty acids from adipose tissues reach their steady-state contribution after about 1-2 h of flight and proteins after 4-5 h (Rothe et al. 1987; Schwilch et al. 1996; Jenni-Eiermann et al. 2002).

Fatty acid supply may be constrained by the enzymatic system of mobilization, proteins transporting fatty acids in the bloodstream and cytoplasm, and translocation across cell membranes (Weber 1992). Many aspects of fuel supply to the working muscles have not yet been studied in birds. However, several avian adaptations are known. In general, the supply of fatty acids is not constrained by adipocyte mobilizations or by mitochondrial oxidation capacity, but rather by perfusion limitations in adipose tissue, circulatory transport, and sarcolemmal uptake (Vock et al. 1996; McWilliams et al. 2004). Although these constrain lipid use in mammals, birds seem to have evolved special mechanisms to overcome these limitations. 
Triglycerides stored in adipocytes need to be hydrolyzed into free fatty acids and glycerol, in order to be released into the blood (Fig. 5.5a). The rate of lipolysis in adipose tissue apparently does not limit the supply of fatty acids, because a large fraction of the fatty acids does not even leave the adipocyte and is re-esterified (Wolfe et al. 1990). Circulatory transport capacity seems to be elevated in birds during endurance flight by several means. Whether an increase in heart size (as shown in several species; Piersma et al. 1996, 1999; Guglielmo and Williams 2003), which may increase cardiac output, facilitates fatty acid transport remains to be shown. The flight muscles of long-distance migrants have a higher capillary density than those of partial migrants and sedentary species and are thus well prepared to supply oxygen and fuel at maximum rates (Lundgren and Kiessling 1988; Maillet and Weber 2007).

Free fatty acids are insoluble in the blood and are thus transported bound to albumin. It is unlikely that albumin concentration can be increased, because of limitations set by blood viscosity and plasma osmotic pressure. Indeed, plasma albumin decreased during flight in pigeons (George and John 1993).

In small passerines, we were surprised to observe elevated concentrations of triglycerides bound in very-low-density lipoproteins VLDL (Jenni-Eiermann and Jenni 1992). We suggested that apart from flight muscles, fatty acids would also be taken up by the liver with its high lipid processing capacity. This would enable plasma albumin to transport more free fatty acids per unit time. Fatty acids taken up by the liver would be re-esterified and released into the plasma in VLDL, a metabolic pathway known from other physiological contexts. This conversion would allow fluxes of large amounts of fatty acids to the flight muscles without a large burden on the plasma and would circumvent the limitations set by albumin to fatty acid transport. However, elevated triglycerides and VLDL have not been observed in other species sampled under experimental flight conditions (Schwilch et al. 1996; Jenni-Eiermann et al. 2002; Pierce et al. 2005). However, flux rather than plasma concentrations should be measured and preferably in birds under natural conditions.

The supply of fatty acids may also be constrained by other steps in the transport system, e.g., into the cell and across the cell membranes (Weber 1992). In birds, high concentrations of heart-type fatty acid binding protein on the membranes of the muscles (FAT/CD36 and FABPpm) and in the cytosol (H-FABP) were found and upregulated during migratory seasons (Guglielmo et al. 1998, 2002; Pelsers et al. 1999; McFarlan et al. 2009). In the flight muscle of a typical migrant (Calidris mauri), the H-FABP concentration was about tenfold greater than in mammalian muscles and $70 \%$ more abundant during the migratory season (Guglielmo et al. 1998, 2002; Guglielmo 2010).

During flight, fatty acids are oxidized by the upregulated enzyme system (CAT, $\beta$-oxidation enzymes such as hydroxyacyl-CoA-dehydrogenase HOAD, citrate synthase, cytochrome oxidase; McWilliams et al. 2004; Maillet and Weber 2007). Fatty acid chain length, degree of unsaturation, and placement of double bonds can affect the rate of mobilization of fatty acids from adipose tissue, utilization by muscles, and possibly performance (Price 2010). 


\subsection{Water Supply During Endurance Flight}

Water may limit endurance flight (Carmi et al. 1992; Klaassen 1996). Birds during experimental flight have been estimated to be sensitive to dehydration in ambient temperatures above about $20{ }^{\circ} \mathrm{C}$ (Giladi and Pinshow 1999; Engel et al. 2006). However, birds flying readily over the Sahara under quite unexpected ambient conditions (mean $30{ }^{\circ} \mathrm{C}, 27 \%$ relative humidity) show that current estimates must be refined (Schmaljohann et al. 2008). Birds incurring dehydration during flight may alleviate or compensate water loss by shifting the composition of fuel types from lipids to more protein which produces 5.9 times more water than an isocaloric amount of lipids (Jenni and Jenni-Eiermann 1998). Recently, an increase in protein catabolism has indeed been demonstrated in water-restricted house sparrows (Gerson and Guglielmo 2010). Migrants caught in the Sahara with emaciated flight muscles and ample lipid stores also hint on such a mechanism.

\subsection{Hormonal Regulation of Flight Metabolism}

Coordinating mechanisms must exist to achieve an adaptive balance between lipid and protein catabolism throughout avian flight. Corticosterone may be involved in the regulation of metabolism during flight and the composition of fuel types used (Jenni et al. 2000). Elevated levels of corticosterone promote gluconeogenesis from amino acids and, thus, increase breakdown of muscle protein (Gwinner et al. 1992; Kettelhut et al. 1988). Studies in free-living small passerines caught during migratory flight (Falsone et al. 2009), in homing pigeons after a $180 \mathrm{~km}$ flight (Haase et al. 1986), and in shorebirds just after landing from a long spring migratory flight (Landys-Cianelli et al. 2002; Reneerkens et al. 2002), showed slightly increased, intermediate corticosterone levels in comparison with resting birds. These data support the hypothesis of an upregulation of corticosterone as a response to increased energy demands. However, in laboratory studies, results were equivocal showing either slightly increased corticosterone levels (ducks and pigeons exercising in a treadmill; Harvey and Phillips 1982; Rees and Harvey 1987) or unchanged levels (pigeons electrically stimulated for 2 h, John and George 1973; red knots flying in a wind tunnel for 2 and $10 \mathrm{~h}$, respectively, Jenni-Eiermann et al. 2009). Whether the latter results might be explained by the experimental situation remains to be shown. In any case, corticosterone increases to variable degrees during flight, but only rises to the very high concentrations typical of an acute stressor when fat deposits are nearly depleted and birds in endurance flight enter phase III of fasting (Gwinner et al. 1992; Jenni et al. 2000). In this case, corticosterone seems to trigger protein catabolism as suggested by the emaciated breast muscles and the high uric acid levels in those individuals (Gwinner et al. 1992; Jenni et al. 2000). The role of other hormones in the regulation of flight metabolism has been investigated in free-flying homing pigeons but not in migrant birds. After a flight of $48 \mathrm{~km}$ or about $1.5 \mathrm{~h}$, significant increases of glucagon, adrenaline, noradrenaline, and growth hormone and either significantly reduced or unchanged 
concentrations of T3 and T4 were found (George et al. 1989; John et al. 1988; Viswanathan et al. 1987). George et al. (1989) concluded that increased sympathetic activity increases glucagon, a lipid-mobilizing hormone. The inconsistent results for T3 and T4 might be explained by differing training protocols. Only the untrained pigeons showed a decrease for thyroid hormone, most probably as a consequence of the activation of the HPA axis, which in turn reduces peripheral T3 formation and suppresses thyroidal T4 secretion (see George et al. 1989 and citations therein).

For insects, octopamine is a hormone that, among other responses to stress, increases trehalose concentration in the hemolymph. Octopamine operates to fuel flight initially with carbohydrates while the flight activity stimulates release of adipose kinetic hormone (AKH) from the corpus cardiacum (Goldsworthy and Joyce 2001). AKH acts directly on the fat body to increase hemolymph lipid concentration, and within $30 \mathrm{~min}$ of flight initiation, fatty acids are the main fuel for flight. Octopamine and $\mathrm{AKH}$ also act directly on flight muscle to enhance metabolism (Steele 1985; Orchard et al. 1993). Although there can be more than one form of AKH in an insect, e.g., the migratory locust has three, the molecules seem to have the same functions and differ only in their half-lives (Goldsworthy and Joyce 2001).

\section{Adaptions to Hunt Out of the Air: Visual Acuity of Birds and Insects}

Hunting out of the air requires extremely good vision. Birds are known to have the best vision among vertebrates, but, depending on the foraging ecology, special features of the eye are required. Species such as raptors for instance, hunting from a considerable height, must be able to detect and focus rapidly moving prey at changing distances. Not surprisingly the wedge-tailed eagle Aquila audax and the American kestrel Falco sparverius exceed the visual acuity of humans more than twice. Species such as swifts, hunting against the bright sky, need a fine-tuned color vision to detect small insects, and nocturnal birds such as owls have to be able to fly and hunt in very low light conditions. Accordingly, a variety of adaptations can be observed in the avian eye.

The first, very obvious, difference between species is the placement of the eye. In most birds, the eyes are situated laterally, enabling only monocular vision but a wide field of view, important for the detection of predators. In contrast, birds of prey typically have their eyes situated more forward and therewith a high overlap of the right and left visual fields enabling binocular vision and depth perception (Fig. 5.6). This is crucial to determine distances and indispensable to successfully capture prey (Evans and Heiser 2004; Martin 2012). Accommodation of the eye is essential to bring objects at varying distances into clear focus. The mechanism of accommodation in the avian eye is mediated by ciliary muscles which move the ciliary processes attached directly at the lens. They exert pressure on the unusually soft and - compared with other vertebrates—pliable lens. By constriction of the iris 


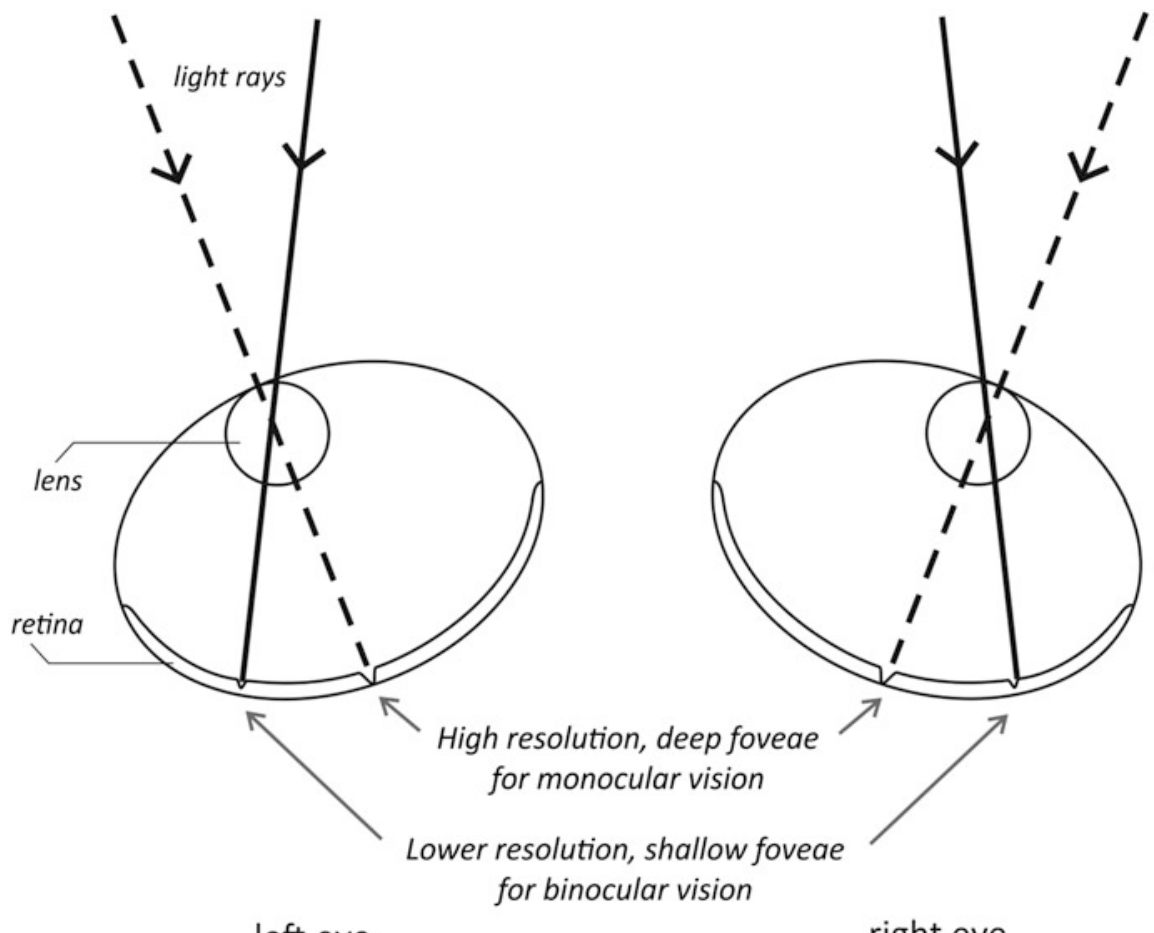

left eye

right eye

Fig. 5.6 Bird eyes are unique in having two foveae, which are shown in this cross-sectional representation of the eyes (adapted from Tucker 2000). The cornea and lens are combined into a single circular idealized lens. Although somewhat controversial, the deeper, centrally located fovea centralis is believed to have higher resolution. For example, a sparrowhawk is thought to have sufficient resolution to see a fly on a branch at $250 \mathrm{~m}$, but its central placement in the retina and the orientation of the eyes on the bird's head generally makes one deep fovea unable to interact with the visual system from the bird's other eye. The forward eyes of owls are an exception. In contrast, the shallow fovea temporalis is positioned laterally such that the foveae from the two eyes interact in binocular vision, improving depth perception during target approach

sphincter, the lens can even be pushed through the pupil. In some bird species, the cornea is also implicated in accommodation, a unique feature of the avian eye. Forming the lens and the cornea to varying shapes together with the varying aperture of the pupil achieves the best possible vision (Martin 1985).

The composition of the retina also varies between species of different foraging ecology. The retina consists of light-sensitive cells, rods, and cones. The closer the packing of the bright-light-sensitive cone cells, the more acuity (resolving power) the animal has (Fig. 5.7a). Raptors for instance have regions on their retina with as much as one million cone cells per square millimeter, enabling their high resolution. Cones enable color vision and are found in high numbers in diurnal birds. The cones of birds are more complex than those of humans. They have four to five distinctive photoreceptor pigments with peak sensitivities in the red, green, blue, 


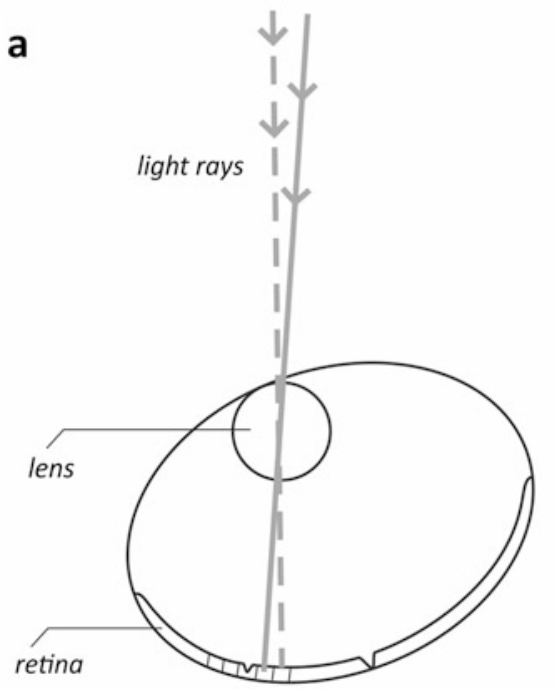

b
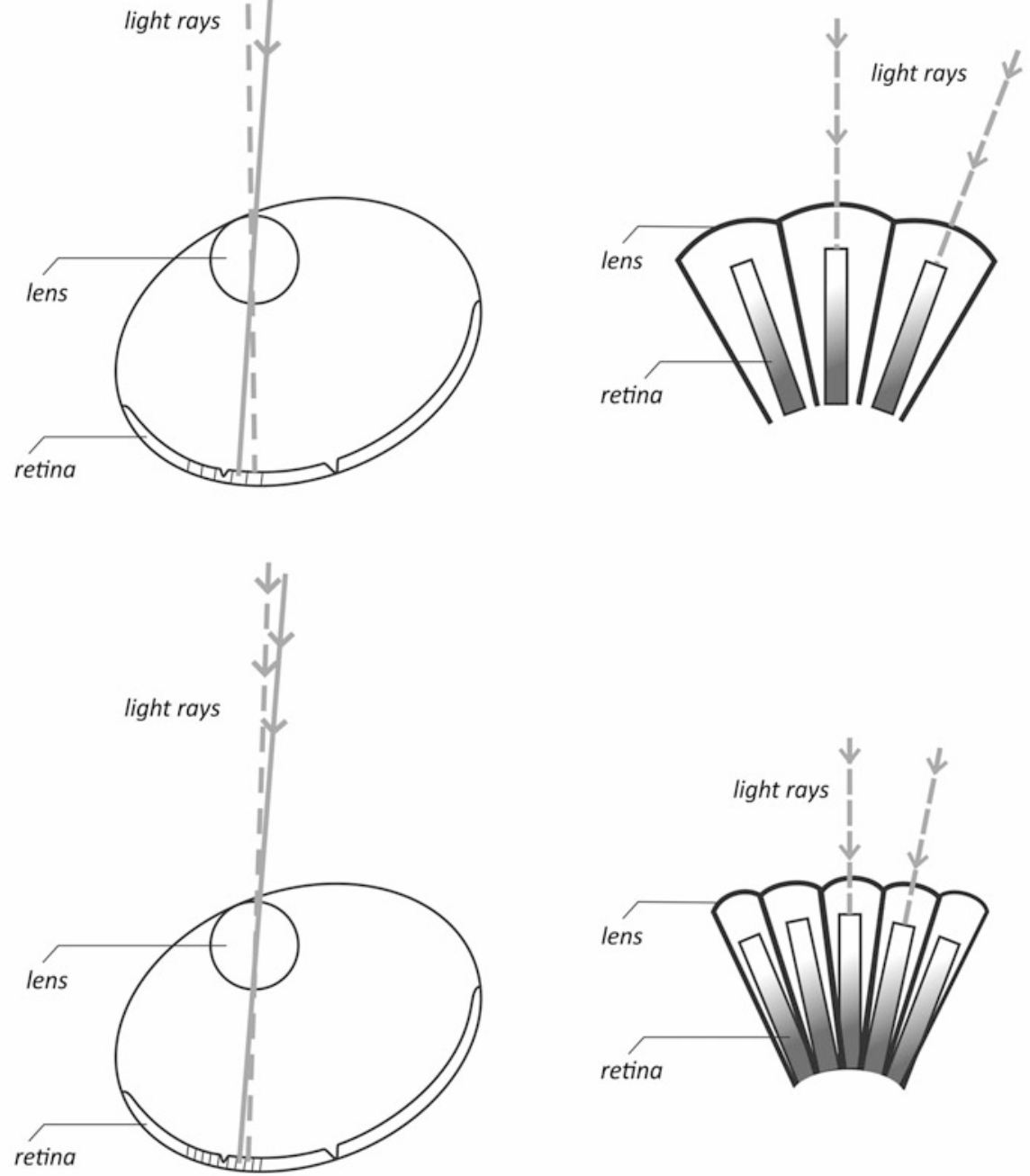

Fig. 5.7 (a) Birds and (b) insects can both increase spatial resolution of their vision by increasing the density of visual sensors. For a cross section of a bird's eye, we show a doubling of retinal cells decreases the angle between the two light rays passing through the lens that are incident on adjacent cells. For a cross section through an insect compound eye, a doubling of ommatidia achieves the same result

and ultraviolet spectrum. Moreover, they contain highly pigmented oil droplets that function as filters, altering and focusing color sensitivity. They may also contain very high concentrations of carotenoids that are thought to act as selective cutoff filters, absorbing short-wave light (Martin 2012; Evans and Heiser 2004). Swallows 
and swifts have only few red and orange droplets, probably to avoid darkening the sky and to enhance the detection of insects (Martin 1985). The highly lightsensitive rods, which do not discriminate colors but do function in dim light, predominate in the retina of nocturnal birds. Nevertheless, acuity of nocturnal birds can be poor and species such as the barn owl Tyto alba rely heavily on auditory cues to detect prey (Güntürkün 2000).

Most birds, as mammals, have in the central part of their retina a circular depression of variable depth and size, the central fovea, where the cones (rods in owls) are most concentrated and the neural layer thinned for the sharpest vision. In addition, hawks and other fast flying diurnal predators have a second fovea in the temporal area of the retina. Hence, they see well on both sides while seeing ahead, because images from each side of their field of view fall on the fovea centralis, providing monocular vision, while images from the front, being the area they are about to enter, fall on the fovea temporalis, which provide acute binocular vision (Fig. 5.6, Tucker 2000; Evans and Heiser 2004).

The compound eyes of insects have poor spatial resolution, and yet many insects pursue targets with remarkable accuracy. In many flies, such as some hoverflies, blowflies, and houseflies, males pursue conspecifics in territorial and mating behaviors. The male eyes have regions with high visual acuity improved by smaller ommatidial angles and larger facets with corresponding retinal adaptations to improve speed and sensitivity of the response (reviewed by Nordström and O'Carroll 2009; Nordström 2012). The threshold for detection of a target is limited by the inter-ommatidial angle (Fig. 5.7b), but larger facets also improve image resolution (Land 1997). Because this acute zone is located in the dorso-frontal portion of the visual field, the flies typically fixate on their target and then give chase from below and behind to copy the moves of the leader. Male fly eyes are also larger and have acute zones with greater spatial resolution than females, allowing stealthy pursuit (Land 1997).

In contrast, other hoverfly species (Collett and Land 1978) and dragonflies (Olberg et al. 2000) calculate the trajectory to anticipate the target's position for contact. They also mainly pursue targets from behind and below to increase contrast of the target against the sky. Dragonfly eyes are unusually large for an insect, allowing a large number of ommatidia with small inter-ommatidial angles in regions of high acuity (0.24-1.8, Land 1997). In addition to the dorso-frontal zone of visual acuity where facets are larger (Olberg et al. 2007), a second frontal zone of high acuity in both sexes might play a role in target fixation nearer to the horizon (Land and Eckert 1985).

\section{$6 \quad$ Concluding Remarks and Future Directions}

This chapter gives background information of how animals adapted anatomically and physiologically to the use of the aerosphere as their main habitat. Only some very conspicuous adaptations were picked out with a special focus on the wings, because they are essential to perform powered flight, and the eyes, because they 
enable foraging in the air. As examples for physiological adaptations we focused on the extraordinary abilities of birds powering endurance flight, unsteady aerodynamics, limitations on weight loading, adaptations for maneuvering, and flying at high altitudes. Of course, there are numerous other specializations such as the hearing of the owls, the echolocation of bats, or orientation and navigation. For detailed studies, the reader is encouraged to deepen his knowledge in other chapters of this book or in specific textbooks.

There are still many gaps in our knowledge of flight physiology or migration behavior, mainly because it is so difficult for a terrestrial creature to investigate and follow a flying animal. Wind tunnels offer the possibility to investigate aerodynamic and physiological aspects of flight under controlled experimental conditions. However, not all species can be trained to fly in a wind tunnel and contradicting results suggest that the conditions in wind tunnels do not always mirror the complex conditions of natural surroundings (e.g., Jenni-Eiermann et al. 2002; Schmaljohann et al. 2008). While migrating naturally across lakes and seas, day-flying moths, butterflies, and dragonflies have been tracked and measured from small boats to address questions concerning where, how, and why they migrate (e.g., Srygley 2001; Srygley et al. 2010). Ever more sophisticated and pervasive ground-based Doppler weather radar have been employed to track migrating bats, birds, and insects (Gauthreaux and Belser 1998; Chilson et al. 2012). Geo-locators (Liechti et al. 2013) or implantable instruments (Bishop et al. 2015) are becoming smaller, lighter, and more refined and open up possibilities to record migration routes or physiological and biomechanical data during flight. Tracking migratory flights of passerines from the International Space Station may also soon be realized (Bridge et al. 2011). These technical developments will help us to investigate new questions and solve the many unknowns of physiological aeroecology.

\section{References}

Alerstam T, Hedenström A, Akesson S (2003) Long-distance migration: evolution and determinants. Oikos 103:247-260

Alexander DE (2002) Nature's flyers. John Hopkins University Press, Baltimore

Altshuler DL, Dudley R (2003) Kinematics of hovering hummingbird flight along simulated and natural elevational gradients. J Exp Biol 206:3139-3147

Altshuler DL, Dickson WB, Vance JT et al (2005) Short-amplitude high-frequency wing strokes determine the aerodynamics of honeybee flight. Proc Nati Acad Sci 102:18213-18218

Battley PF, Dekinga A, Dietz MW et al (2001) Basal metabolic rate declines during long-distance migratory flight in great knots. Condor 103:838-845

Bicudo JEPW, Buttemer WA, Chappell MA et al (2010) Ecological and environmental physiology of birds. Oxford University Press, New York

Biesel W, Nachtigall W (1987) Pigeon flight in a wind tunnel. IV Thermoregulation and water homeostasis. J Comp Physiol B 157:117-128

Birch JM, Dickinson MH (2003) The influence of wing-wake interactions on production of aerodynamic forces in flight. J Exp Biol 206:2257-2272

Bishop CM, Spivey RJ, Hawkes LA et al (2015) Th roller coaster flight strategy of bar-headed geese conserves energy during Himalayan migrations. Science 347:250-254 
Bomphrey RJ, Taylor GK, Thomas ALR (2009) Smoke visualization of free-flying bumblebees indicates independent leading-edge vortices on each wing pair. Exp Fluids 46:811-821

Bridge ES, Thorup K, Bowlin MS, Chilson PB, Diehl RH, Fleron RW, Hartl P, Kays R, Kelly JF, Robinson WD, Wikelski M (2011) Technology on the move: recent and forthcoming innovations for tracking migratory birds. Bioscience 61:689-698

Butler PJ, Woakes AJ (2001) Seasonal hypothermia in a large migrant bird: saving energy for fat deposition? J Exp Biol 204:1361-1367

Butler PJ, Woakes AJ, Bishop CM (1998) Behaviour and physiology of Svalbard barnacle geese Branta leucopsis during their autumn migration. J Avian Biol 29:536-545

Carey C, Morton ML (1976) Aspects of circulatory physiology of montane and lowland birds. Comp Biochem Physiol 54A:61-74

Carmi N, Pinshow B, Porter WP et al (1992) Water and energy limitations on flight duration in small migrating birds. Auk 109(2):268-276

Chai P, Dudley R (1996) Limits to flight energetics of hummingbirds hovering in hypodense and hypoxic gas mixtures. J Exp Biol 199:2285-2295

Chai P, Srygley RB (1990) Predation and the flight, morphology, and temperature of Neotropical rainforest butterflies. Am Nat 135:48-765

Chapman JW, Reynolds DR, Mouritsen H et al (2008) Wind selection and drift compensation optimize migratory pathways in a high-flying moth. Curr Biol 18:514-518

Chilson PB, Frick WF, Kelly JF, Howard KW, Larkin RP, Diehl RH, Westbrook JK, Kelly TA, Kunz TH (2012) Partly cloudy with a chance of migration: weather, radars, and aeroecology. Bull Am Meteorol Soc 93:669-686

Collett TS, Land MF (1978) How hoverflies compute interception courses. J Comp Physiol 125:191-204

Costantini D, Cardinale M, Carere C (2007) Oxidative damage and anti-oxidant capacity in two migratory bird species at a stop-over site. Comp Biochem Physiol C 144:363-371

Crabtree B, Newsholme EA (1975) Comparative aspects of fuel utilization and metabolism by muscle. In: Usherwood PNR (ed) Insect muscle. Academic, New York, pp 405-491

Dickinson MH, Lehmann FO, Sane SP (1999) Wing rotation and the aerodynamic basis of insect flight. Science 284:1954-1956

Dillon ME, Dudley R (2014) Surpassing Mt. Everest: extreme flight performance of alpine bumble-bees. Biol Lett 10:20130922

Dillon ME, Frazier MR (2006) Drosophila melanogaster locomotion in cold thin air. J Exp Biol 209:364-371

Dohm GL (1986) Protein as a fuel for endurance exercise. Exerc Sport Sci Rev 14:143-173

Dudley R (ed) (2000) The biomechanics of insect flight: form, function, evolution. Princeton University Press, Princeton

Dudley R, Vermeij GJ (1992) Do the power requirements of flapping flight constrain folivory in flying animals? Funct Ecol 6:101-104

Ellington CP (1984) Aerodynamics of flapping flight. Am Zool 24:95-105

Ellington CP, Van den Berg C, Willmott AP et al (1996) Leading-edge vortices in insect flight. Nature 384:626-630

Engel S, Biebach H, Visser GH (2006) Water and heat balance during flight in the rose-colored starling (Sturnus roseus). Physiol Biochem Zool 79:763-774

Esch H (1988) The effects of temperature on flight muscle potentials in honeybees and cuculiinid winter moths. J Exp Biol 135:109-117

Esterhuizen N, Clusella-Trullas S, van Daalen CE et al (2014) Effects of within-generation thermal history on the flight performance of Ceratitis capitata: colder is better. J Exp Biol 217:3545-3556

Evans HE, Heiser JB (2004) What's inside: anatomy and physiology. In: Podulka S, Rohrbaugh RW Jr, Bonney R (eds) Handbook of bird biology, 2nd edn. Cornell Lab of Ornithology, Ithaca (chapter 4) 
Falsone K, Jenni-Eiermann S, Jenni L (2009) Corticosterone in migrating songbirds during endurance flight. Horm Behav 56:548-556

Gannes LZ, Hatch KA, Pinshow B (2001) How does time since feeding affect the fuels pigeons use during flight? Physiol Biochem Zool 74:1-10

Gauthreaux SA Jr, Belser CG (1998) Display of bird movements on the WSR-88D: patterns and quantification. Weather Forecast 13:453-464

George JC, John TM (1993) Flight effects on certain blood parameters in homing pigeons (Columba livia). Comp Biochem Physiol 106A:707-712

George JC, John TM, Mitchell MA (1989) Flight effects on plasma levels of lipid, glucagon and thyroid hormones in homing pigeons. Horm Metab Res 21:542-545

Gerson AR, Guglielmo CG (2010) House sparrows (Passer domesticus) increase protein catabolism in response to water restriction. Am J Regul Integr Comp Physiol 300:R925-R930

Gibo DL (1981) Altitudes attained by migrating monarch butterflies, Danaus p. plexippus (Lepidoptera: Danaidae), as reported by glider pilots. Can J Zool 59:571-572

Giladi I, Pinshow B (1999) Evaporative and excretory water loss during free flight in pigeons. J Comp Physiol B 169:311-318

Goldsworthy GJ, Joyce M (2001) Physiology and endocrine control of flight. In: Woiwod IP, Reynolds DR, Thomas CD (eds) Insect movement: mechanisms and consequences. CABI, Wallingford, pp 65-86

Greenlee KJ, Harrison JF (2004) Development of respiratory function in the American locust Schistocerca Americana. I. Across-instar effects. J Exp Biol 207:497-508

Guglielmo CG (2010) Move that fatty acid: fuel selection and transport in migratory birds and bats. Integr Comp Biol 50:336-345

Guglielmo CG, Williams TD (2003) Phenotypic flexibility of body composition in relation to migratory stage, age, and sex in the Western sandpiper (Calidris mauri). Physiol Biochem Zool 76:84-98

Guglielmo CG, Haunerland NH, Williams TD (1998) Fatty acid binding protein, a major protein in the flight muscle of the Western Sandpiper. Comp Biochem Physiol 119B:549-555

Guglielmo CG, Piersma T, Williams TD (2001) A sport-physiological perspective on bird migration: evidence for flight-induced muscle damage. J Exp Biol 204:2683-2690

Guglielmo CG, Haunerland NH, Hochachka PW, Williams TD (2002) Seasonal dynamics of flight muscle fatty acid binding protein and catabolic enzymes in a long-distance migrant shorebird. Am J Physiol Regul Intgr Comp Physiol 282:R1405-R1413

Güntürkün O (2000) Sensory physiology: vision. In: Whittow GC (ed) Sturkie's avian biology, 5th edn. Academic, San Diego, pp 1-14

Gwinner E, Zeman M, Schwabl-Benzinger I et al (1992) Corticosterone levels of passerine birds during migratory flight. Naturwissenschaften 79:276-278

Haase E, Rees A, Harvey S (1986) Flight stimulates adrenocortical activity in pigeons (Columba livia). Gen Comp Endocrinol 61:424-427

Harrison JF, Lighton JR (1998) Oxygen-sensitive flight metabolism in the dragonfly Erythemis simplicicollis. J Exp Biol 201:1739-1744

Harrison JF, Roberts SP (2000) Flight respiration and energetics. Annu Rev Physiol 62:179-205

Harvey S, Phillips JG (1982) Adrenocortical responses of ducks to treadmill exercise. J Endocrinol 94:141-146

Hasselquist D, Lindström ̊̊, Jenni-Eiermann S et al (2007) Long flights do not influence immune responses of a long-distance migrant bird: a wind-tunnel experiment. J Exp Biol 210:1123-1131

Jenni L, Jenni-Eiermann S (1998) Fuel supply and metabolic constraints in migrating birds. J Avian Biol 29:521-528

Jenni L, Jenni-Eiermann S, Spina F et al (2000) Regulation of protein breakdown and adrenocortical response to stress in birds during migratory flight. Am J Physiol Reg Integr Comp Physiol 278:R1182-R1189 
Jenni-Eiermann S, Jenni L (1992) High plasma triglyceride levels in small birds during migratory flight: a new pathway for fuel supply during endurance locomotion at very high mass-specific metabolic rates. Physiol Zool 65:112-123

Jenni-Eiermann S, Jenni L, Kvist A et al (2002) Fuel use and metabolic response to endurance exercise: a wind tunnel study of a long-distance migrating shorebird. J Exp Biol 205:2453-2460

Jenni-Eiermann S, Hasselquist D, Lindström Å et al (2009) Are birds stressed during long-term flights? A wind tunnel study on circulating corticosterone in the red knot. Gen Comp Endocrinol 164:101-106

Jenni-Eiermann S, Jenni L, Smith S et al (2014) Oxidative stress in endurance flight: an unconsidered factor in bird migration. PLoS One. https://doi.org/10.1371/journal.pone.0097650

John TM, George JC (1973) Effect of prolonged exercise on levels of plasma glucose, free fatty acids and corticosterone and muscle free fatty acids in the pigeon. Arch Int Physiol Bioch 81:421-425

John TM, Viswanathan M, George JC et al (1988) Flight effects on plasma levels of free fatty acids, growth hormone and thyroid hormones in homing pigeons. Horm Metab Res 20:271-271

Johnson CG (1969) Migration and dispersal of insects by flight. Methuen, London

Jones G, Rydell J (2003) Attack and defense: Interactions between echolocating bats and their insect prey. In: Kunz TH, Fenton MB (eds) Bat ecology. University of Chicago, Chicago, pp 301-345

Kettelhut IC, Wing SS, Goldberg AL (1988) Endocrine regulation of protein breakdown in skeletal muscle. Diabetes Metab Rev 4:751-772

Kingsolver JG, Srygley RB (2000) Experimental analyses of body size, flight and survival in pierid butterflies. Evol Ecol Res 2:593-612

Klaassen M (1996) Metabolic constraints on long-distance migration in birds. J Exp Biol 199:57-64

Kunz TH, Ingalls KA (1994) Folivory in bats: an adaptation derived from frugivory. Funct Ecol 8:665-668

Land MF (1997) Visual acuity in insects. Annu Rev Entomol 42:147-177

Land MF, Eckert H (1985) Maps of the acute zones of fly eyes. J Comp Physiol A 156:525-538

Landys-Cianelli MM, Ramenofsky M, Piersma T et al (2002) Baseline and stress-induced plasma corticosterone during long-distance migration in the bar-tailed godwit, Limosa lapponica. Physiol Biochem Zool 75:101-110

Landys-Ciannelli MM, Piersma T, Jukema J (2003) Strategic size changes of internal organs and muscle tissue in the bar-tailed godwit during fat storage on a spring stopover site. Funct Ecol 17:151-179

Lehmann FO (2008) When wings touch wakes: understanding locomotor force control by wakewing interference in insect wings. J Exp Biol 211:224-233

Liechti F, Witvliet W, Weber R et al (2013) First evidence of a 200-day non-stop flight in a bird. Nat Commun 4:2554. https://doi.org/10.1038/ncomms3554

Lundgren BO, Kiessling KH (1988) Comparative aspects of fibre types, areas, and capillary supply in the pectoralis muscle. J Comp Physiol B 158:165-173

Maillet D, Weber JM (2007) Relationship between n-3 PUFA content and energy metabolism in the flight muscles of a migrant shorebird: evidence for natural doping. J Exp Biol 210:413-423

Maina JN (2006) Development, structure, and function of a novel respiratory organ, the lung-air sac system of birds: to go where no other vertebrate has gone. Biol Rev 81:545-579

Marden JH, Chai P (1991) Aerial predation and butterfly design: how palatability, mimicry and flight constrain mass allocation. Am Nat 138:15-36

Marsh R (1983) Adaptations of the Gray Catbird (Dumetella carolinensis) to long distance migration: energy stores and substrate concentrations in plasma. Auk 100:70-179

Martin GR (1985) Eye. In: King AS, McLelland J (eds) Form and function in birds, vol 3. Academic, London, pp 311-374 
Martin GR (2012) Through birds' eyes: insights into avian sensory ecology. J Ornithol 153 (Suppl 1):S23-S48

McCracken GF, Gillam EH, Westbrook JK et al (2008) Brazilian free-tailed bats (Tadarida brasiliensis: Molossidae, Chiroptera) at high altitude: links to migratory insect populations. Integr Comp Biol 48:107-118

McCracken KG, Barger CP, Bulgarella M et al (2009) Parallel evolution in the major haemoglobin genes of eight species of Andean waterfowl. Mol Ecol 18:3992-4005

McFarlan JT, Bonen A, Guglielmo CG (2009) Seasonal up-regulation of protein mediated fatty acid transport in flight muscles of migratory white-throated sparrows (Zonotrichia albicollis). J Exp Biol 212:2934-2940

McWilliams SE, Guglielmo CG, Pierce B et al (2004) Flying, fasting, and feeding in birds during migration: a nutritional and physiological ecology perspective. J Avian Biol 35:377-393

Mujires F, Johansson LC, Barfield R et al (2008) Leading-edge vortex improves lift in slow-flying bats. Science 319:1250-1253

Norberg UM (ed) (1990) Vertebrate flight. Springer, Berlin

Norberg UM, Rayner JMV (1987) Ecological morphology and flight in bats (Mammalia: Chiroptera): wing adaptations, flight performance, foraging strategy and echolocation. Philos Trans R Soc Lond B 316:335-427

Nordström K (2012) Neural specializations for small target detection in insects. Curr Opin Neurobiol 22:272-278

Nordström K, O'Carroll DC (2009) Feature detection and the hypercomplex property in insects. Trends Neurosci 32:383-391

Olberg RM, Worthington AH, Venator KR (2000) Prey pursuit and interception in dragonflies. J Comp Physiol A 186:155-162

Olberg RM, Seaman RC, Coats MI et al (2007) Eye movements and target fixation during dragonfly prey-interception flights. J Comp Physiol A 193:685-693

Orchard I, Ramirez J-M, Lange AB (1993) A multifunctional role for octopamine in locust flight. Annu Rev Entomol 38:227-249

Pelsers MMAL, Butler PJ, Bishop CM et al (1999) Fatty acid binding protein in heart and skeletal muscles of the migratory barnacle goose throughout development. Am J Phys 276:R637-R643

Pennycuick CJ (1998) Computer simulation of fat and muscle burn in long-distance bird migration. J Theor Biol 191:47-61

Pennycuick CJ (ed) (2008) Modelling the flying bird. Elsevier, Amsterdam

Pierce B, McWilliams SR, O'Connor TP et al (2005) Effect of dietary fatty acid composition on depot fat and exercise performance in a migrating songbird, the red-eyed vireo. J Exp Biol 208:1277-1285

Piersma T, Gill RE Jr (1998) Guts don't fly: small digestive organs in obese Bar-tailed Godwits. Auk 115:196-203

Piersma T, Lindström $\AA$ (1997) Rapid reversible changes in organ size as a component of adaptive behaviour. Trends Ecol Evol 12:134-138

Piersma T, Everaarts JM, Jukema J (1996) Build-up of red blood cells in refuelling Bar-tailed Godwits in relation to individual migratory quality. Condor 98:363-370

Piersma T, Gudmundsson GA, Lilliendahl K (1999) Rapid changes in the size of different functional organ and muscle groups during refueling in a long-distance migrating shorebird. Physiol Biochem Zool 72:405-415

Portugal SJ, Hubel TY, Fritz J et al (2014) Upwash exploitation and downwash avoidance by flap phasing in ibis formation flight. Nature 505:399-402

Price ER (2010) Dietary lipid composition and avian migratory flight performance: development of a theoretical framework for avian fat storage. Comp Biochem Physiol A 157:297-309

Ratcliffe JM, Nydam ML (2008) Multimodal warning signals for a multiple predator world. Nature 455:96-99

Rees A, Harvey S (1987) Adrenocortical responses of pigeons (Columba livia) to treadwheel exercise. Gen Comp Endocrinol 65:117-120 
Reneerkens J, Morrison RIG, Ramenofsky M et al (2002) Baseline and stress-induced levels of corticosterone during different life cycle substages in a shorebird on the high arctic breeding grounds. Physiol Biochem Zool 75:200-208

Reynolds AM, Reynolds DR (2009) Aphid aerial density profiles are consistent with turbulent advection amplifying flight behaviours: abandoning the epithet 'passive'. Proc R Soc B 276:137-143

Reynolds DR, Chapman JW, Edwards AS (2005) Radar studies of the vertical distributions of insects migrating over southern Britain: the influence of temperature inversions on nocturnal layer concentrations. Bull Entomol Res 95:259-274

Roberts TJ, Weber JM, Hoppeler H et al (1996) Design of the oxygen and substrate pathways II. Defining the upper limits of carbohydrates and fat oxidation. J Exp Biol 199:1651-1658

Rothe HJ, Biesel W, Nachtigall W (1987) Pigeon flight in a wind tunnel. II Gas exchange and power requirements. J Com Physio B 157:99-10

Sahlin K, Katz A, Broberg S (1990) Tricarboxylic acid cycle intermediates in human muscle during prolonged exercise. Am J Phys 259:C834-C841

Scheid P, Slama H, Piiper J (1972) Mechanisms of the unidirectional flow in parabronchi of avian lungs: measurements in duck lung preparations. Respir Physiol 14:83-95

Schmaljohann H, Liechti F (2009) Adjustments of wingbeat frequency and air speed to air density in free-flying migratory birds. J Exp Biol 212:3633-3642

Schmaljohann H, Bruderer B, Liechti F (2008) Sustained bird flights occur at temperatures far beyond expected limits. Anim Behav 76:1133-1138

Schmaljohann H, Liechti F, Bruderer B (2009) Trans-Sahara migrants select flight altitudes to minimize energy costs rather than water loss. Behav Ecol Sociobiol 63:1609-1619

Schmidt-Nielsen K (ed) (1984) Scaling: why is animal size so important? Cambridge University Press, Cambridge

Schmidt-Nielsen K (ed) (1997) Animal physiology, 5th edn. Cambridge, University Press

Schwilch R, Jenni L, Jenni-Eiermann S (1996) Metabolic responses of homing pigeons to flight and subsequent recovery. J Comp Physiol B 166:77-87

Schwilch R, Piersma T, Holmgren NMA et al (2002) Do migratory birds need a nap after a long non-stop flight? Ardea 90(1):149-154

Scott GR (2011) Elevated performance: the unique physiology of birds that fly high altitudes. J Exp Biol 214:2455-2462

Scott I, Evans PR (1992) The metabolic output of avian (Sturnus vulgaris, Calidris alpina) adipose tissue liver and skeletal muscle: implications for BMR/body mass relationships. Comp Biochem Physiol 103A:329-332

Scott GR, Milsom WK (2007) Control of breathing and adaption to high altitude in the bar-headed goose. Am J Phys Regul Integr Comp Phys 293:R379-R391

Scott GR, Schulte PM, Egginton S et al (2011) Molecular evolution of cytochrome c oxidase underlies high-altitude adaptation in the bar-headed goose. Mol Biol Evol 28:351-363

Scott GR, Hawkes LA, Frappell PB (2015) How bar-headed geese fly over the Himalayas. Physiology 30:107-115

Speakman JR, Thomas DW (2003) Physiological ecology and energetics of bats. In: Kunz TH, Fenton MB (eds) Bat ecology. University of Chicago, Chicago, pp 430-490

Speakman JR, Hays GC, Webb PI (1994) Is hyperthermia a constraint on the diurnal activity of bats? J Theor Biol 171:325-341

Srygley RB (2001) Compensation for fluctuations in crosswind drift without stationary landmarks in butterflies migrating over seas. Anim Behav 61:191-203

Srygley RB, Chai P (1990a) Flight morphology of Neotropical butterflies: palatability and distribution of mass to the thorax and abdomen. Oecologia 84:491-499

Srygley RB, Chai P (1990b) Predation and the elevation of thoracic temperature in brightly colored Neotropical butterflies. Am Nat 135:766-787

Srygley RB, Dudley R (1993) Correlations of the position of center of body mass with butterfly escape tactics. J Exp Biol 174:155-166 
Srygley RB, Dudley R (2008) Optimal strategies for insects migrating in the flight boundary layer: mechanisms and consequences. Integr Comp Biol 48:119-133

Srygley RB, Kingsolver JG (1998) Red-wing blackbird reproductive behaviour and the palatability, flight performance, and morphology of temperate pierid butterflies (Colias, Pieris, and Pontia). Biol J Linn Soc 64:41-55

Srygley RB, Kingsolver JG (2000) Effects of weight loading on flight performance and survival of palatable Neotropical Anartia fatima butterflies. Biol J Linn Soc 70:707-725

Srygley RB, Thomas ALR (2002) Unconventional lift-generating mechanisms in free-flying butterflies. Nature 420:660-664

Srygley RB, Dudley R, Oliveira EG et al (2010) El Niño and dry season rainfall influence hostplant phenology and an annual butterfly migration from Neotropical wet to dry forests. Glob Chang Biol 16:936-945

Steele JE (1985) Control of metabolic processes. In: Kerkut GA, Gilbert LI (eds) Endocrinology II, Comprehensive insect physiology, biochemistry, and pharmacology, vol 8. Pergamon Press, Oxford, pp 99-145

Stockwell EF (2001) Morphology and flight manoeuvrability in New World leaf-nosed bats (Chiroptera: Phyllostomidae). J Zool 254:505-514

Swartz SM, Freeman PW, Stockwell EF (2003) Ecomorphology of bats: comparative and experimental approaches relating structural design to ecology. In: Kunz TH, Fenton MB (eds) Bat ecology. University of Chicago, Chicago, pp 257-300

Swartz SM, Breuer KS, Willis DJ (2008) Aeromechanics in aeroecology: flight biology in the aerosphere. Integr Comp Biol 48:85-89

Taylor RAJ, Reling D (1986) Density/height profile and long-range dispersal of first-instar gypsy moth (Lepidoptera: Lymantriidae). Environ Entomol 15:431-435

Thomas ALR, Taylor GK, Srygley RB et al (2004) Dragonfly flight: free-flight and tethered flow visualizations reveal a diverse array of unsteady lift generating mechanisms, controlled primarily via angle of attack. J Exp Biol 207:4299-4323

Thomson SC, Speakman JR (1999) Absorption of visible spectrum radiation by the wing membranes of living pteropodid bats. J Comp Physiol B 169:187-194

Tucker VA (2000) The deep fovea, sideways vision and spiral flight paths in raptors. J Exp Biol 203:3745-3754

Usherwood JR, Stavrou M, Lowe JC et al (2011) Flying in a flock comes at a cost in pigeons. Nature 474:494-497

Videler JJ (ed) (2005) Avian flight. Oxford University Press, Oxford

Videler JJ, Stamhuis EJ, Povel GDE (2004) Leading-edge vortex lifts swifts. Science 306:1960-1962

Viswanathan M, JohnTM GJC et al (1987) Flight effects on plasma glucose, lactate, catecholamines and corticosterone in homing pigeons. Horm Metab Res 19:400-402

Vock R, Weibel ER, Hoppeler H et al (1996) Design of the oxygen and substrate pathways. V. Structural basis of vascular substrate supply to muscle cells. J Exp Biol 199:1675-1688

Voigt CC, Lewanzik D (2011) Trapped in the darkness of the night: thermal and energetic constraints of daylight flight in bats. Proc R Soc B 278:2311-2317

Ward S, Rayner JMV, Möller U et al (1999) Heat transfer from starlings Sturnus vulgaris during flight. J Exp Biol 202:1589-1602

Warrick DR (1998) The turning- and linear-maneuvering performance of birds: the cost of efficiency for coursing insectivores. Can J Zool 76:1063-1079

Warrick DR, Tobalske BW, Powers DR (2005) Aerodynamics of the hovering hummingbird. Nature 435:1094-1097

Weber JM (1992) Pathways for oxidative fuel provision to working muscles: ecological consequences of maximal supply limitations. Experientia 48:557-564

Weber JM, Roberts TJ, Vock R et al (1996a) Design of the oxygen and substrate pathways. III Partitioning energy provision from carbohydrates. J Exp Biol 199:1659-1666 
Weber JM, Brichon G, Zwingelstein G et al (1996b) Design of the oxygen and substrate pathways. IV. Partitioning energy provision from fatty acids. J Exp Biol 199:1667-1674

Westbrook JK (2008) Noctuid migration in Texas within the nocturnal aeroecological boundary layer. Integr Comp Biol 48:99-106

Wolfe RR, Klein S, Carraro F et al (1990) Role of triglyceride-fatty acid cycle in controlling fat metabolism in humans during and after exercise. Am J Phys 258:E382-E389

Yanoviak SP, Dudley R, Kaspari M (2005) Directed aerial descent in canopy ants. Nature 433:624-626

Yanoviak SP, Kaspari M, Dudley R (2009) Gliding hexapods and the origins of insect aerial behaviour. Biol Lett 5:510-512 